\title{
Pten Mutations Alter Brain Growth Trajectory and Allocation of Cell Types through Elevated $\beta$-Catenin Signaling
}

\author{
ํㅏoujun Chen, Wen-Chin Huang, Julien Séjourné, Amy E. Clipperton-Allen, and Damon T. Page \\ Department of Neuroscience, The Scripps Research Institute, Jupiter, Florida 33458
}

\begin{abstract}
Abnormal patterns of head and brain growth are a replicated finding in a subset of individuals with autism spectrum disorder (ASD). It is not known whether risk factors associated with ASD and abnormal brain growth (both overgrowth and undergrowth) converge on common biological pathways and cellular mechanisms in the developing brain. Heterozygous mutations in PTEN $\left(\right.$ PTEN $\left.^{+/-}\right)$, which encodes a negative regulator of the PI3K-Akt-mTOR pathway, are a risk factor for ASD and macrocephaly. Here we use the developing cerebral cortex of $\mathrm{Pten}^{+/-}$mice to investigate the trajectory of brain overgrowth and underlying cellular mechanisms. We find that overgrowth is detectable from birth to adulthood, is driven by hyperplasia, and coincides with excess neurons at birth and excess glia in adulthood. $\beta$-Catenin signaling is elevated in the developing $\mathrm{Pten}^{+/-}$cortex, and a heterozygous mutation in Ctnnb1 (encoding $\beta$-catenin), itself a candidate gene for ASD and microcephaly, can suppress Pten $^{+/-}$cortical overgrowth. Thus, a balance of Pten and $\beta$-catenin signaling regulates normal brain growth trajectory by controlling cell number, and imbalance in this relationship can result in abnormal brain growth.
\end{abstract}

Key words: autism; $\beta$-catenin; brain growth; cell types; macrocephaly; Pten

\section{Significance Statement}

We report that Pten haploinsufficiency leads to a dynamic trajectory of brain overgrowth during development and altered scaling of neuronal and glial cell populations. $\beta$-catenin signaling is elevated in the developing cerebral cortex of Pten haploinsufficient mice, and a heterozygous mutation in $\beta$-catenin, itself a candidate gene for ASD and microcephaly, suppresses Pten ${ }^{+/-}$cortical overgrowth. This leads to the new insight that Pten and $\beta$-catenin signaling act in a common pathway to regulate normal brain growth trajectory by controlling cell number, and disruption of this pathway can result in abnormal brain growth.

\section{Introduction}

Reports that some children with autism spectrum disorder (ASD) have relatively large heads date back to the first description of autism (Kanner, 1943). In intervening years, the finding of early overgrowth of the head (macrocephaly) and brain in ASD has been reported in some, but not all, studies (for review, see Courchesne et al., 2007; Raznahan et al., 2013). This discrepancy likely reflects the fact that

Received Dec. 26, 2014; revised June 4, 2015; accepted June 11, 2015.

Author contributions: Y.C. and D.T.P. designed research; Y.C., W.-C.H., J.S., A.E.C.-A., and D.T.P. performed research; D.T.P. contributed unpublished reagents/analytic tools; Y.C., W.-C.H., J.S., A.E.C.-A., and D.T.P. analyzed data; Y.C., W.-C.H., J.S., A.E.C.-A., and D.T.P. wrote the paper.

This work was supported by gift funds from Ms. Nancy Lurie Marks, startup funds from The Scripps Research Institute, and Simons Foundation Grant Award 360712 to D.T.P. Y.C. was supported by an 0'Keeffe Neuroscience Scholars Award. W.-C.H. was supported by the Fraternal Order of Eagles. We thank Ms. Trina Kemp for administrative support.

The authors declare no competing financial interests.

Correspondence should be addressed to Dr. Damon T. Page, Department of Neuroscience, The Scripps Research Institute, 130 Scripps Way, Jupiter, FL 33458. E-mail: paged@scripps.edu.

DOI:10.1523/JNEUROSCI.5272-14.2015

Copyright $\odot 2015$ the authors $\quad 0270-6474 / 15 / 3510252-16 \$ 15.00 / 0$ head and brain overgrowth occurs in a subset of the remarkably heterogeneous population of individuals with ASD, which includes individuals with microcephaly. Because of rapidly expanding knowledge of contributing genetic factors, extreme variations in head and brain size have been proposed as a candidate biomarker to help stratify the ASD population into biologically and clinically meaningful subgroups (Klein et al., 2013; Stessman et al., 2014). However, several fundamental gaps exist in our knowledge regarding abnormal brain growth and ASD, including the precise trajectory of atypical growth, the cell types and brain areas impacted, and the relationship between altered growth of the brain and the symptoms of ASD. Addressing these gaps in a clinical population presents challenges given the genetic and phenotypic heterogeneity among ASD individuals and the paucity of postmortem samples across developmental stages. Thus, a complementary approach of investigating well-defined genetic risk factors associated with ASD and extreme variations in head and brain size can help us understand whether these risk factors may influence brain development via common biological pathways and cellular mechanisms. 
The gene PTEN (Phosphatase and tensin homolog) provides an entry point into this problem: PTEN encodes a phosphatidylinositol-3,4,5-trisphosphate 3-phosphatase that acts as a canonical negative regulator of the PI3K-Akt-mTOR pathway. Mutations in PTEN are reported in $\sim 20 \%$ of individuals with ASD and macrocephaly (Butler et al., 2005; Buxbaum et al., 2007; Varga et al., 2009; McBride et al., 2010). Extreme variations in head circumference are associated with de novo mutations in PTEN (macrocephaly) and components of the Wnt- $\beta$-catenin pathway (microcephaly and macrocephaly) in individuals with ASD (O'Roak et al., 2012; Stessman et al., 2014). Importantly, tissue growth and cell number are influenced by both Pten and $\beta$-catenin via Akt and GSK-3 $\beta$ signaling (Cross et al., 1995; Aberle et al., 1997; Sun et al., 1999). Furthermore, Pten and $\beta$-catenin have independently been shown to play roles in both neurogenesis and gliogenesis (Groszer et al., 2001; Chenn and Walsh, 2002; Fraser et al., 2004 ), and mice with elevated $\beta$-catenin signaling display brain overgrowth due to excess cell number (Chenn and Walsh, 2002). We have previously reported that adult mice with germline haploinsufficiency for Pten $\left(\right.$ Pten $\left.^{+/-}\right)$demonstrate both brain overgrowth and social behavioral deficits that are relevant to ASD (Page et al., 2009; Clipperton-Allen and Page, 2014).

Based on these observations, we hypothesize that Pten haploinsufficiency alters brain growth trajectory and scaling of neuronal and glial populations through elevated $\beta$-catenin signaling. Here we make use of Pten haploinsufficient mice to test this hypothesis and address three related questions: (1) What is the trajectory of brain overgrowth caused by Pten haploinsufficiency? (2) What drives brain overgrowth caused by Pten haploinsufficiency? (3) Does Pten act in a common pathway with other risk genes associated with ASD and extreme variation in head and brain size to regulate brain growth?

\section{Materials and Methods}

Mice. All animal experiments were conducted in accordance with National Institutes of Health and Association for Assessment and Accreditation of Laboratory Animal Care guidelines and were approved by The Scripps Research Institute's Institutional Animal Care and Use Committee.

Mice of the B6.129-Pten ${ }^{\text {tmIRps }}$ line (Podsypanina et al., 1999) were obtained from the repository at the National Cancer Institute at Frederick, where they were already backcrossed onto a congenic C57BL/6J background by the donating investigator. The line has been maintained by backcrossing to $\mathrm{C} 57 \mathrm{BL} / 6 \mathrm{~J}$ mice for $>10$ generations. Mice used in this study were generated by crossing Pten $^{\text {tmlRps/+ }}\left(\right.$ Pten $\left.^{+/-}\right)$mice with WT $\left(\right.$ Pten $\left.^{+/+}\right)$mice. All other mouse lines have been described previously and were obtained from the Jackson Laboratory; these consisted of Gt(ROSA)26Sor rm34.1(CAG-Syp/tdTomato)Hze (Synaptophysin-tdTomato, stock \#012570), Tg(TCF/Lef1-HIST1H2BB/EGFP)61Hadj/J (TCF/Lef: H2B-GFP, stock \#013752) (Ferrer-Vaquer et al., 2010), Rptor ${ }^{\text {tmlLex }}$ (Rptor $^{+/-}$, stock \#013191) (Guertin et al., 2006), Pten ${ }^{\text {tmlHwu }}$ (Pten ${ }^{\text {loxP/loxP }}$, stock \#006440) (Lesche et al., 2002), Ctnnb1 ${ }^{\text {tm2Kem }}$ (Ctnnb1 $1^{\text {loxP/loxP }}$, stock \#004152) (Brault et al., 2001), Mtor ${ }^{\text {tm 1.2Koz }}$ (Mtor ${ }^{\text {loxP/loxP }}$, stock \#011009) (Risson et al., 2009), and Emxl ${ }^{\text {tml(cre)Krj }}$ (Emxl-Cre ${ }^{+}$; stock \#005628) (Gorski et al., 2002). To obtain Emxl-Cre ${ }^{+}$: Pten $^{\text {loxP/+ }}$; Ctnnb1 $1^{\text {loxP/+ }}$ mice, Pten ${ }^{\text {loxP/+ }}$; Ctnnbl $1^{\text {loxP/+ }}$ male mice were mated with Emxl-Cre ${ }^{+}$; $\mathrm{Pten}^{\text {loxP } /+}$; Ctnnb1 ${ }^{\text {loxP/+ }}$ female mice. WT, Emxl-Cre ${ }^{-}$, and Emxl$\mathrm{Cre}^{+} ;$Pten $^{+1+} ; \mathrm{Ctnnb1}^{+/+}$mice were used as controls. To obtain Emx1$\mathrm{Cre}^{+} ; \mathrm{Pten}^{\text {loxP/+}} ; \mathrm{Mtor}^{\text {loxP/+ }}$ mice, Pten $^{\text {loxP/+ }} ; \mathrm{Mtor}^{\text {loxP/+ }}$ male mice were mated with Emxl-Cre ${ }^{+}$; ten $^{\text {loxP/+ }}$; Mtor ${ }^{\text {loxP/+ }}$ female mice. WT, Emxl$\mathrm{Cre}^{-}$, and Emxl-Cre ${ }^{+} ; \mathrm{Pten}^{+/+} ; \mathrm{Mtor}^{+/+}$mice were used as controls. Mouse genotypes were confirmed by PCR using genomic DNA isolated from tail or ear samples.
Isotropic fractionator. Isotropic fractionator was used to determine total cell number and cell type ratio in the cortex as described previously (Herculano-Houzel and Lent, 2005). Briefly, following perfusion with $4 \%$ PFA, mouse brains were fixed in 4\% PFA for 1 week. Brains at P0 were then dissected into the cerebral cortex and remainder, whereas adult brains were dissected into the cerebral cortex, cerebellum, olfactory bulbs, and remainder. After dissection, the cerebral cortex was mechanically dissociated using a $7 \mathrm{ml}$ glass tissue homogenizor (Kontes Glass) in standard solution ( $1 \%$ Triton X-100 in $40 \mathrm{~mm}$ sodium citrate). Nuclei in the homogenate were then stained with DAPI (Invitrogen, catalog \#D3571), and the total nuclei number was counted using a hemocytometer (Fisher Scientific, catalog \#0267110). For each brain, $10 \mu \mathrm{l}$ nuclei homogenate samples was loaded into a hemocytometer, and nuclei from $0.1 \mu \mathrm{l}$ of each sample were counted. This process was done four times for each animal, and the average was used to calculate the total cortical nuclei number of each mouse. To obtain the ratio of neuronal to non-neuronal cells, nuclei were stained with both anti-NeuN antibody (1:500, Abcam, catalog \#104225) and DAPI; at least 500 nuclei stained with DAPI were counted, and the ratio of neurons was calculated by dividing the number of $\mathrm{NeuN}^{+}$nuclei by the total nuclei number. To obtain the ratio of different glial types, microglia marker anti-Ibal (1:500, Wako, catalog $\# 019-19741)$, astrocyte marker anti-S100 $\beta$ (1:500, Sigma, catalog \#S2532), and oligodendrocyte marker anti-Olig2 (1:1000, Millipore, catalog \#AB9610) were used to stain nuclei, and the number of each glial cell type was counted. Anti-Ki67 (1:1000, Abcam, catalog \#AB15580) and anti-NeuN (1:500, Abcam, catalog \#AB104225) were used to determine the number of proliferating cells and neurons within the cerebral cortex at E14.5. Anti-Ctip2 (1:1000, Abcam, catalog \#AB18465) and anti-Cux1 (1:500, Santa Cruz Biotechnology, catalog \#sc-13024) were used to count populations of deep- and upper-layer neurons, respectively, within the cerebral cortex.

To estimate the rate of "false positives" we might encounter using this approach, we double-stained nuclei with anti-NeuN and anti-Ibal antibodies and counted nuclei positive for both markers. We found that $\sim 2 \%$ of nuclei are positive for both anti-NeuN and anti-Ibal antibodies. Because $\mathrm{NeuN}^{+}$(neurons) and $\mathrm{Ibal}^{+}$(microglia) cells are two distinct populations, we think this provides us with an estimate of error that occurs during the quantification process, likely due to immunoreactive cellular debris overlying nuclei.

To confirm that mice carrying only Emx1-Cre or the loxP alleles used in this study show no effects on brain mass or cell number and were thus valid to use as controls, Emx1-Cre $e^{-}$; loxP $P^{-}$(WT), Emx1-Cre ${ }^{-}$; lox $P^{+}$, and $E m x 1-C r e^{+} ; \operatorname{lox} P^{-}$mice were compared. No significant differences in brain mass, brain anatomical region mass, cortex cell number, or cell density were observed among these groups (data not shown); thus, data from these mice were pooled and defined as controls.

Immunohistochemistry. Mouse brains were fixed in 4\% PFA, incubated in a $20 \%$ sucrose/PBS solution at $4^{\circ} \mathrm{C}$ for $2 \mathrm{~d}$, and embedded in TissueTek OCT compound (Sakura). Coronal or sagittal sections were collected on Superfrost/Plus slides and immunostained with the following antibodies. Primary antibodies used in this study include anti-NeuN (1:2000), anti-Ibal (1:500), anti-GFAP (1:2000, Invitrogen, catalog \#130300), anti-Olig2 (1:1000), anti-Ki67 (1:5000), anti-BrdU (1:5000, Abcam, catalog \#AB6326), anti-cleaved caspase 3 (1:5000, Cell Signaling Technology Technology, catalog \#9661S), anti-Ctip2 (1:2000), and antiCux1 (1:500). AlexaFluor-488, -594, and -647-conjugated secondary antibodies (1:2000) were purchased from Invitrogen. DAPI was used for nuclear labeling (Invitrogen, catalog \#D3571). Images were obtained with an Olympus VS120 microscope and processed using the VSDESKTOP software (Olympus).

Laminar plots of anti-NeuN-immunostained sections were generated as follows: after image acquisition, ROIs were cropped from the cortex across the radial thickness using Photoshop (Adobe). Cortex thickness was normalized, and images were then auto-adjusted for each channel and saved. Plot profiles for each channel of each image were obtained using Image (http://imagej.nih.gov/ij/). Three brains from each genotype, and 2 images and 2-3 ROIs (a total of 5-6 ROIs from each brain), were analyzed.

To estimate neuronal and total cell density within the histological sections of the somatosensory cerebral cortex at P0 and adulthood, 250- 
$\mu \mathrm{m}$-wide columns that span the radial thickness of the somatosensory cortex were defined as ROIs. These columns were divided into 10 bins of equal size in the radial axis. For each animal, two adjacent ROIs from each of three plane-matched sagittal sections were analyzed. In each bin, neuron number $\left(\mathrm{NeuN}^{+}\right)$and total cell number $\left(\mathrm{DAPI}^{+}\right)$were counted, and density for each marker was calculated by dividing the counts by the area within each bin. Three brains from each genotype were analyzed.

To assay neuronal apoptosis in the developing cerebral cortex, sagittal sections of $\mathrm{P} 4$ cortex were immunostained using antibodies recognizing cleaved caspase 3 (CC3) and NeuN. The whole of the cortex, or the upper and deep layers, were defined as ROIs; and for each animal, counts of cells positive for both markers were obtained from three plane-matched sections. Three animals from each genotype were analyzed.

Analysis of cell cycle exit. Dams carrying E14.5 embryos were injected intraperitoneally with $100 \mu \mathrm{g} \mathrm{BrdU/g}$ body weight and killed $24 \mathrm{~h}$ after injection. Immunohistochemical staining with anti-BrdU and anti-Ki67 was performed following the above-mentioned procedure. Two hundred fifty-micrometer-wide columns that span the entire radial thickness of the medial cortex were defined as ROIs. For each animal, two adjacent ROIs from each of three plane-matched sagittal sections were analyzed. The ratio of cells exiting the cell cycle was calculated by dividing the number of $\mathrm{BrdU}^{+}, \mathrm{Ki}^{+}{ }^{-}$cells by the total number of $\mathrm{BrdU}^{+}$cells $\left(\mathrm{BrdU}^{+}, \mathrm{Ki}^{-} 7^{-} / \mathrm{BrdU}^{+}\right)$. Three animals per genotype were analyzed.

Western blot analysis. P0 pups from each genotype were decapitated and cortical tissue was dissected, rapidly frozen, and stored at $-80^{\circ} \mathrm{C}$ until used. Tissue was homogenized in RIPA buffer containing Protease Inhibitor Mixture (Roche) and phosphatase inhibitors. Total protein concentrations were measured using Pierce BCA Protein Assay Kit (ThermoScientific), and samples were diluted for equal amounts of protein in each lane. Proteins were electrophoresed onto NuPAGE $4 \%-12 \%$ Bis-Tris Gel (Novex, Invitrogen) and were subsequently transferred to PVDF membranes (Immobilon, Millipore). Immunoblots were blocked with 5\% BSA (Sigma) in PBS (Invitrogen) for $1 \mathrm{~h}$, and incubated with primary antibodies in $1 \% \mathrm{BSA}$ at $4^{\circ} \mathrm{C}$ overnight. All antibodies were purchased from Cell Signaling Technology: phospho-Akt (S473; 1:1000, \#4060), Akt (1:1000, \#2920), phospho-S6 (S235/236; 1:2000, \#4858), S6 (1:1000, \#2217), phospho-GSK-3 $\alpha / \beta$ (1:1000, \#9331), GSK-3 $\beta$ (1:1000, $\# 9315)$, and $\beta$-actin (1:2000,\#4970). Membranes were then incubated with peroxidase-conjugated anti-mouse (Akt) or anti-rabbit (all others) IgG secondary antibodies (1:20,000, Jackson ImmunoResearch Laboratories). Proteins were visualized with enhanced chemiluminescence using WesternBright Quantum kit (Advansta) and quantified using ImageJ. For each protein of interest, a ratio of phospho-protein/total protein was calculated. Normalized values were expressed as a ratio of the mean expression level of controls. Graphs represent an average of at least two different technical replicates from at least three different animals.

Analysis of $\beta$-catenin reporter mice. Images were acquired using identical acquisitions parameters on an Olympus VS120 microscope equipped with a $20 \times$ objective. For each genotype, two sections, matched for sectioning plane, from each of three animals were analyzed. An experimenter blind to the identity of images opened them in Photoshop and applied auto-adjustment of the image levels. The cerebral cortex was defined as an ROI, and gray value (mean) and integrated density were measured. This same ROI was then exported to ImageJ and analyzed as follows: Image $>$ Adjust $>$ Threshold $>$ Auto, and then Analyze $>$ Analyze Particles. Particle size was selected so that only individual $\mathrm{GFP}^{+}$nuclei were counted.

Statistical analysis. Independent-sample $t$ tests were used to compare the Pten ${ }^{+/-}$and Pten ${ }^{+/+}$mice, and adult Emxl-Cre ${ }^{+/-} ;$Pten $^{\text {loxP } /+}$ and control mice. For the P0 Emx1-Cre; Pten ${ }^{\text {loxP }}$ line, one-way ANOVAs were used to assess genotype effects, and planned comparison independentsample $t$ tests compared heterozygous and homozygous conditional Pten mutations, as well as each genotype to controls. Genotype effects were assessed in Emxl-Cre; Pten ${ }^{\text {loxP }}$; Mtor ${ }^{\text {loxP }}$ and Emx1-Cre; Pten ${ }^{\text {loxP }}$; Ctnnb1 $1^{\text {loxP }}$ conditional mouse lines, as well as the Pten ${ }^{+/-} ;$Rptor $^{+/-}$ line, by one-way ANOVA, with Tukey's post hoc tests as appropriate. All statistics were performed using Excel or PASW 18 (IBM), with significance set at $p<0.05$. Statistics for nonsignificant results are not shown.

\section{Results}

Trajectory of brain growth in germline $\mathrm{Pten}^{+/-}$mice

Adult germline Pten ${ }^{+/-}$mice of both sexes show elevated brain mass without a corresponding change in body mass (Page et al., 2009; Clipperton-Allen and Page, 2014), and thus are a model of absolute and relative brain overgrowth in adulthood. To obtain a trajectory of altered brain growth associated with germline Pten haploinsufficiency, we measured brain mass across developmental stages. Increased mass was observed in male Pten ${ }^{+/-}$mice at all postnatal ages (Fig. 1A), including birth (postnatal day 0, P0; $\left.t_{(48)}=5.91, p<0.001\right), \mathrm{P} 4\left(t_{(30)}=4.32, p<0.001\right), \mathrm{P} 7\left(t_{(17)}=\right.$ $2.81, p=0.012), \mathrm{P} 14\left(t_{(12)}=4.62, p<0.001\right), \mathrm{P} 30\left(t_{(7)}=6.35\right.$, $p<0.001$ ), and adulthood (P56 or older; $t_{(23)}=15.30, p<$ $0.001)$. The magnitude of increase in brain mass relative to WT littermates varied with age, with the smallest difference between genotypes at $\mathrm{P} 7$ and the greatest difference between genotypes at P0 and adulthood (Fig. 1B). Body mass, however, was similar between Pten ${ }^{+1-}$ mice and WT controls at all ages except birth, when Pten $^{+/-}$mice weighed more than WT $\left(t_{(48)}=4.64, p<\right.$ 0.001; Fig. $1 C)$. Pten ${ }^{+/-}$led to overgrowth across brain regions at P0 (cerebral cortex: $t_{(14)}=2.68, p=0.018$; remainder: $t_{(14)}=$ 2.48, $p=0.026$; Fig. $1 D, E)$ and adulthood (cerebral cortex: $t_{(12)}$ $=9.30, p<0.001$; cerebellum: $t_{(12)}=3.03, p=0.010$; olfactory bulb: $t_{(12)}=2.64, p=0.022$; remainder: $t_{(12)}=7.92, p<0.001$; Fig. $1 H, I)$. A similar magnitude of brain overgrowth was also observed in female Pten ${ }^{+/-}$mice at P0 (brain mass: $93.73 \pm 1.45$ $\mathrm{mg}$ in WT controls, and $103.19 \pm 1.32 \mathrm{mg}$ in Pten ${ }^{+/-}$mice; $t_{(14)}$ $=4.82, p<0.001$ ) and adulthood (brain mass: $419.34 \pm 6.35 \mathrm{mg}$

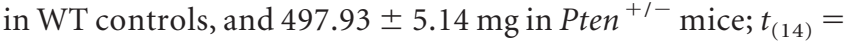
$9.61, p<0.001$ ), suggesting that the trajectory of brain growth is grossly similar in male and female Pten $^{+/-}$mice.

Among the potential underlying causes for brain overgrowth in Pten ${ }^{+/-}$mice are cellular hypertrophy (increased cell size) or hyperplasia (increased cell number). Mutations in Pten are known to influence both of these processes (for review, see Stiles et al., 2004). In the following experiments, we dissociated the relative contributions of altered cell number (hyperplasia) and density (a reflection of cell size and spacing) to Pten ${ }^{+/-}$brain overgrowth.

\section{Cell number is increased in the cerebral cortex of newborn and adult germline Pten $^{+/-}$mice}

Abnormal structure and function of the cerebral cortex have been reported across studies of individuals with ASD, including delayed frontal cortex maturation (Zilbovicius et al., 1995), increased cortex size (Piven et al., 1996; Courchesne, 2002; Carper and Courchesne, 2005), increased neuronal number in the prefrontal cortex (Courchesne et al., 2011), and altered molecular networks (Boylan et al., 2007; Voineagu et al., 2011). Our previous and current results also indicate that the size and mass of Pten $^{+/-}$cortex are increased, so we focused our study on the cerebral cortex. To ascertain whether cell number is changed in Pten $^{+/-}$cortex, we applied the isotropic fractionator technique (Herculano-Houzel and Lent, 2005) to the cortices of WT and Pten $^{+/-}$mice at P0 and adulthood. Total cell number was increased in Pten ${ }^{+/-}$cortex at both stages (P0: $t_{(14)}=3.63, p=$ 0.003; adult: $t_{(12)}=5.20, p<0.001$; Fig. $\left.1 F, J\right)$. No significant genotype difference in cortical cell density was observed (Fig. $1 G, K)$. These results show that hyperplasia coincides with Pten haploinsufficiency-induced cortex overgrowth, whereas a change in gross cell density was not detected. 

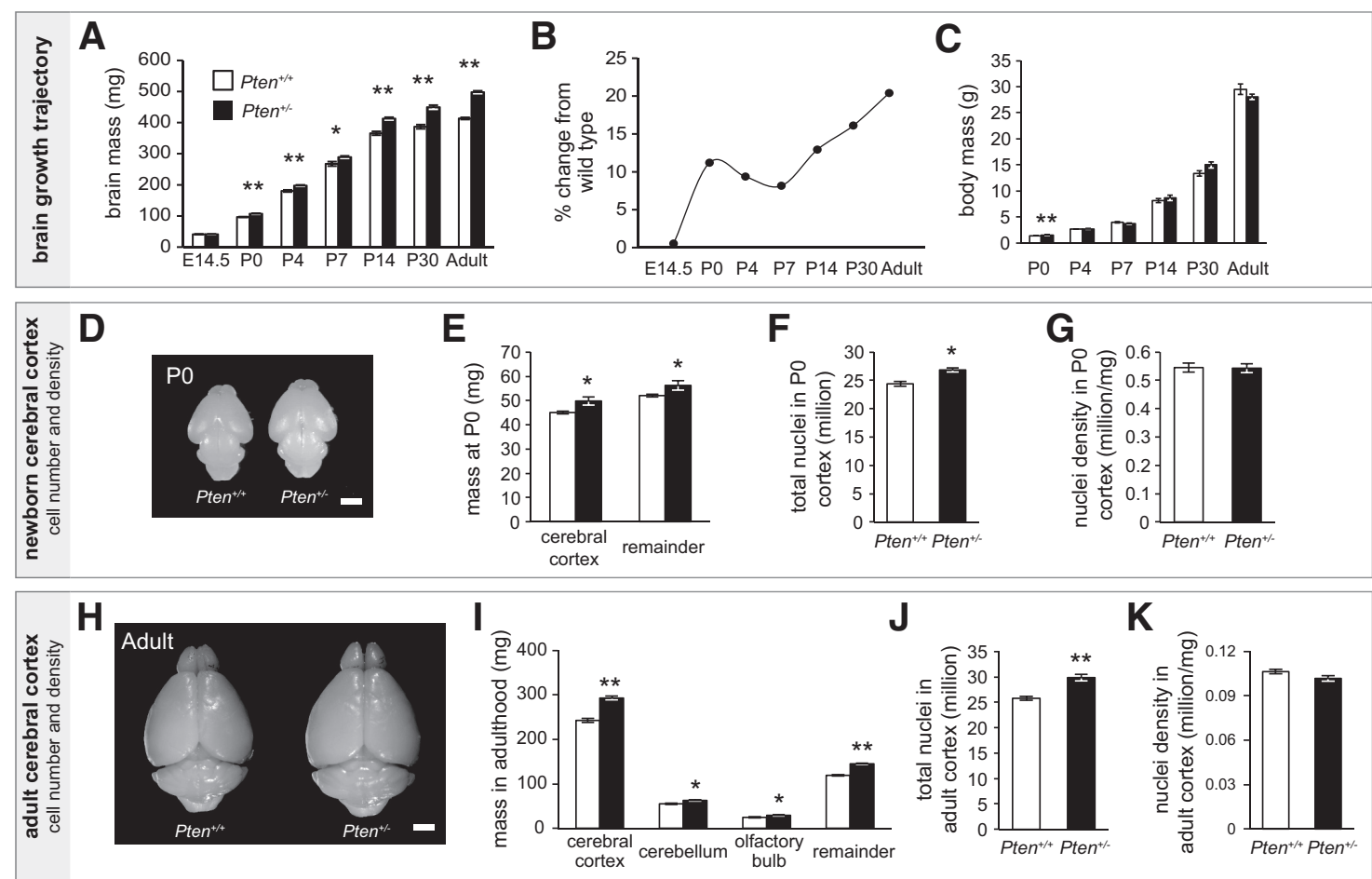

Figure 1. Germline Pten ${ }^{+/-}$mice show brain overgrowth and hyperplasia of the cerebral cortex from birth. $\boldsymbol{A}$, Developmental trajectory of brain growth. Brains of Pten ${ }^{+/-}$mice are heavier than those of WT $\left(\right.$ Pten ${ }^{+/+}$) mice from postnatal day 0 (P0) to adulthood. B, Difference from WT of Pten ${ }^{+/-}$brain mass calculated by the following: (Pten ${ }^{+/-}$brain mass - WT brain mass)/WT brain mass $\times 100$. C, Body mass at different ages. Pten ${ }^{+/-}$mice are heavier than WT mice at PO, but not at other stages. $\boldsymbol{D}, \boldsymbol{H}$, Representative WT and Pten ${ }^{+/-}$brains at P0 $(\boldsymbol{D})$ and adulthood $(\boldsymbol{H})$. Scale bars, $2 \mathrm{~mm}$. $\boldsymbol{E}, \boldsymbol{I}$, Brain region mass at $\mathrm{PO}(\boldsymbol{E})$ and adulthood $(\boldsymbol{I})$. All anatomical regions are heavier in Pten ${ }^{+/-}$compared with WT mice. $\boldsymbol{F}, \boldsymbol{J}$, Total nuclei number is increased within $P$ ten ${ }^{+/-}$ cerebral cortex at both $\mathrm{PO}(\boldsymbol{F})$ and adulthood $(\boldsymbol{J})$, as determined by isotropic fractionator. $\mathbf{G}, \boldsymbol{K}$, Nuclei density within cerebral cortex at P0 ( $\boldsymbol{G}$ ) and adulthood $(\boldsymbol{K})$. No significant difference is observed between WT and Pten ${ }^{+/-}$, as determined by isotropic fractionator. E15.5, Embryonic day 15.5; P0, postnatal day 0. ${ }^{*} p<0.05 .{ }^{* *} p<0.001 . \boldsymbol{A}-\boldsymbol{C}$, E14.5:Pten ${ }^{+/+}, n=12 ;$ Pten ${ }^{+/-}, n=10$. P0: Pten $^{+/+}, n=29 ;$ Pten $^{+/-}, n=21$ P4:Pten ${ }^{+/+}, n=17 ;$ Pten $^{+/-}, n=13$ P7:Pten ${ }^{+/+}, n=9 ;$ Pten $^{+/-}, n=10$. P14:Pten ${ }^{+/+}, n=10 ;$ Pten $^{+/-}, n=4$. P30:Pten $^{+/+}, n=4 ;$ Pten $^{+/-}$, $n=5$. Adult: Pten ${ }^{+/+}, n=13 ;$ Pten $^{+/-}, n=12 . \mathbf{E}-\mathbf{G}$, Pten $^{+/+}, n=10 ;$ Pten $^{+/-}, n=6 . \boldsymbol{I}_{-\boldsymbol{K}}$, Pten $^{+/+}, n=7 ;$ Pten $^{+/-}, n=7$. Data are mean \pm \pm SEM.

\section{Excess neurons in the cerebral cortex of newborn, but not} adult, germline Pten $^{+/-}$mice

The dynamic changes in brain mass in developing Pten ${ }^{+/-}$mice compared with WT (Fig. $1 B$ ) could be due to differential allocation of neuronal and glial cell types in Pten ${ }^{+/-}$cortex, reflecting the sequential production of neurons and glia during corticogenesis. To test this, we measured neuron number by staining nuclei with anti-NeuN antibody (which labels neuronal nuclei) together with DAPI (which labels all nuclei). We found that the $\mathrm{NeuN}^{+} /$ total nuclei $\left(\mathrm{DAPI}^{+}\right)$ratio was significantly higher in $\mathrm{Pten}^{+/-}$ cortex at birth $\left(t_{(12)}=3.24, p=0.007\right.$; Fig. $\left.2 A\right)$, with a corresponding increase in the total number of $\mathrm{NeuN}^{+}$cells $\left(t_{(12)}=\right.$ 4.45, $p<0.001$; Fig. $2 B$ ), while the number of NeuN negative $\left(\mathrm{NeuN}^{-}\right)$cells was similar to WT (Fig. $2 C$ ). Thus, hyperplasia in the newborn Pten ${ }^{+/-}$cortex is caused by an expanded neuronal population.

We next assessed neuronal number in adult $\mathrm{Pten}^{+/-}$cortex. Strikingly, and in contrast to our findings in the newborn cortex, at adulthood we found that the $\mathrm{NeuN}^{+} / \mathrm{DAPI}^{+}$ratio was significantly lower in Pten $^{+-}$than WT cortex $\left(t_{(12)}=4.21, p=0.001\right.$; Fig. $\left.2 I\right)$. Although the total number of $\mathrm{NeuN}^{+}$cells did not differ between genotypes (Fig. $2 J$ ), the number of $\mathrm{NeuN}^{-}$cells was significantly increased in Pten ${ }^{+-}$cortex $\left(t_{(12)}=6.44, p<0.001\right.$; Fig. $\left.2 K\right)$.

Immunohistochemistry and laminar plot analysis of $\mathrm{NeuN}$ signal suggested that the gross organization of the cortex was intact in Pten ${ }^{+-}$animals at P0 and in adulthood (Fig. $2 E, F, M, N)$. Interestingly, overall cortex thickness was increased in Pten ${ }^{+/-}$mice at P0 (Fig. 2D), but not in adulthood (Fig. $2 L$ ). Counting cell density across the radial thickness of the cortex by bins, we found that at $\mathrm{P} 0$, total cell $\left(\mathrm{DAPI}^{+}\right)$density was similar between WT control and Pten ${ }^{+/-}$cortices, with the exception of a slight difference in the deepest bins (Fig. 2G). In contrast, neuronal $\left(\mathrm{NeuN}^{+}\right)$density was significantly increased in a bin that includes the upper layers of the cortical plate in $\mathrm{Pten}^{+/-}$mice (Fig. $2 H$ ). In adulthood, total cell density was similar between WT control and Pten ${ }^{+/-}$cortices, with the exception of a significant decrease in bins corresponding to upper layers in $\mathrm{Pten}^{+/-}$ mice (Fig. 2O). Neuronal density was significantly decreased in bins corresponding to upper layers, as well as deep layers, in adult Pten $^{+/-}$cortex (Fig. 2P). These results are consistent with the isotropic fractionator results, which indicate that the total neuron number is not changed in adulthood. In the context of an enlarged cortex with grossly normal total cell density, this implies a decrease in neuronal density.

\section{Markers of proliferation, lamination, and apoptosis in the} developing cerebral cortex of germline Pten ${ }^{+/-}$mice One possible explanation for the increased neuron number at birth is increased neural progenitor cell proliferation during neurogenesis. To test this possibility, we quantified the number of proliferating $\left(\mathrm{Ki}^{+} 7^{+}\right)$cells at embryonic day 14.5 (E14.5) using isotropic fractionator. No differences were found between WT and Pten $^{+/-}$mice for brain mass (Fig. $1 A, B$ ), total cell number, cell density, and $\mathrm{NeuN}^{+} / \mathrm{DAPI}^{+}$ratio (Fig. $3 A-D$ ) at E14.5. In contrast, the $\mathrm{Ki} 7^{+} / \mathrm{DAPI}^{+}$ratio and the total number of $\mathrm{Ki}^{+} 7^{+}$ cells were significantly increased in Pten ${ }^{+/-}$cortex (Fig. 3 E, F), indicating that Pten ${ }^{+/-}$mice have more neural progenitors undergoing proliferation at E14.5. In addition, when we examined 

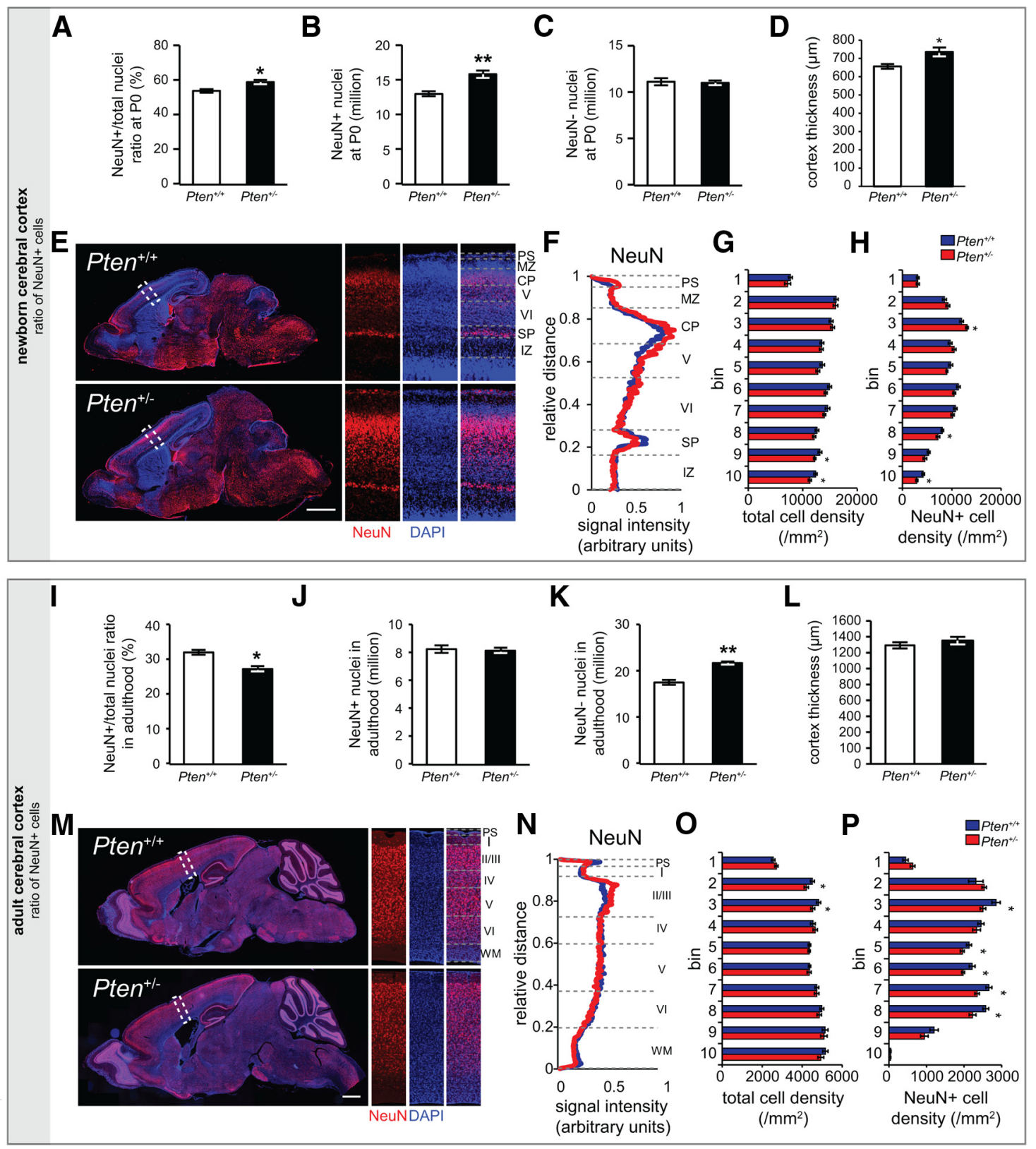

Figure 2. Neuron number is increased in the cerebral cortex of germline Pten ${ }^{+-}$mice at birth but not in adulthood. $A, I$, Ratio of nuclei positive for NeuN (neuronal marker, NeuN ${ }^{+}$) to total nuclei $\left(\mathrm{DAPI}^{+}\right)$. NeuN ${ }^{+} / \mathrm{DAPI}^{+}$ratio is increased in Pten ${ }^{+/-}$cortex at PO $(\boldsymbol{A})$ and decreased in adulthood $(\boldsymbol{I}) . \boldsymbol{B}, \boldsymbol{J}$, Number of NeuN ${ }^{+}$nuclei in the cortex. NeuN ${ }^{+}$nuclei number is increased $\mathrm{Pten}^{+/-}$cortex at $\mathrm{PO}(\boldsymbol{B})$ but is similar to that of WT cortex in adulthood $(\boldsymbol{J}) . \boldsymbol{C}, \boldsymbol{K}$, Number of NeuN ${ }^{-}$(non-neuronal) nuclei in the cortex. The number of NeuN ${ }^{-}$nuclei is similar between Pten ${ }^{+/-}$ and WT cortices at PO $(\boldsymbol{C})$ and higher in adult Pten ${ }^{+/-}$cortex $(\boldsymbol{K}) . \boldsymbol{D}, \boldsymbol{L}$, The thickness of the cerebral cortex (somatosensory cortex, measured from ventricle to pial surface) is greater than WT in Pten $^{+/-}$brain at P0 (D) but not in adulthood (L). $\boldsymbol{E}, \boldsymbol{M}$, Sagittal brain sections immunostained with anti-NeuN antibody (red) and DAPI (nuclear marker; blue) at P0 (E) and in adulthood ( $\boldsymbol{M}$ ). Top left panel, WT $\left(P t e n^{+/+}\right)$brain section. Bottom left panel, Pten ${ }^{+/-}$brain section. Right panels, Enlarged views of cerebral cortex from the inset of the left panels. Scale bars, 1 mm. PS, Pial surface; $\mathrm{MZ}$, marginal zone; $\mathrm{CP}$, cortical plate; I, layer I; II/III, layer II/III; V, layer V; VI, layer VI; SP, subplate; IZ, intermediate zone; WM, white matter. $\boldsymbol{F}, \mathbf{N}$, Laminar plot analysis of anti-NeuN immunostaining indicates that $P$ Pen haploinsufficiency does not alter gross cortical organization at $\mathrm{PO}(\boldsymbol{F})$ or in adulthood $(\boldsymbol{N}) . \mathbf{G}, \mathbf{0}$, Count of DAPI ${ }^{+}$cell density in WT and Pten ${ }^{+/}$somatosensory cortex at $\mathrm{PO}(\boldsymbol{G})$

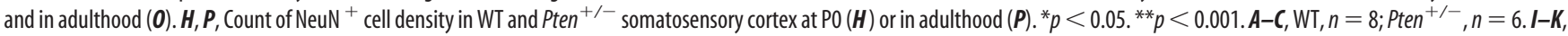
$\mathrm{WT}, n=7 ;$ Pten $^{+/-}, n=7 . \boldsymbol{D}, \mathbf{G}, \boldsymbol{H}, \mathbf{L}, \mathbf{O}, \boldsymbol{P}, n=3$ per genotype. Scale bars: $\boldsymbol{E}, \boldsymbol{M}, 1 \mathrm{~mm}$. Data are mean \pm SEM.

exit from the cell cycle by BrdU pulse treatment at E14.5, and immunostaining for BrdU and Ki67 at E15.5, we found that the ratio of $\mathrm{BrdU}^{+}$, $\mathrm{Ki}^{-} 7^{-} / \mathrm{BrdU}^{+}$(ratio of progenitors exiting cell cycle) was significantly decreased in Pten ${ }^{+/-}$cortex $(p<0.001$; Fig. 3G,H). Thus, Pten ${ }^{+-}$mice have more proliferating cells and a decreased ratio of cells exiting the cell cycle.

These observations led us to hypothesize that Pten haploinsufficiency results in a relative increase in upper-layer neurons, the majority of which are born after E14.5. To test this hypothesis, we counted Cux ${ }^{+}$(upper-layer) and Ctip2 ${ }^{+}$(deep-layer) nuclei at $\mathrm{P} 0$. We found an increase in the Cux $1^{+} / \mathrm{DAPI}^{+}$ratio and the total number of $\mathrm{Cuxl}^{+}$nuclei in Pten ${ }^{+/-}$cortex at birth. The $\mathrm{Ctip}^{+} / \mathrm{DAPI}^{+}$ratio was not significantly changed, but the total number of Ctip $2^{+}$neurons displayed a trend toward an increase $(p=0.07)$ in Pten $^{+/-}$cortex relative to WT (Fig. 3I-K). Because total neuron number is not significantly different between WT and $\mathrm{Pten}^{+/-}$cortices in adulthood, we predicted that the excess $\mathrm{Cux}^{+}{ }^{+}$neurons are eliminated during postnatal development. 

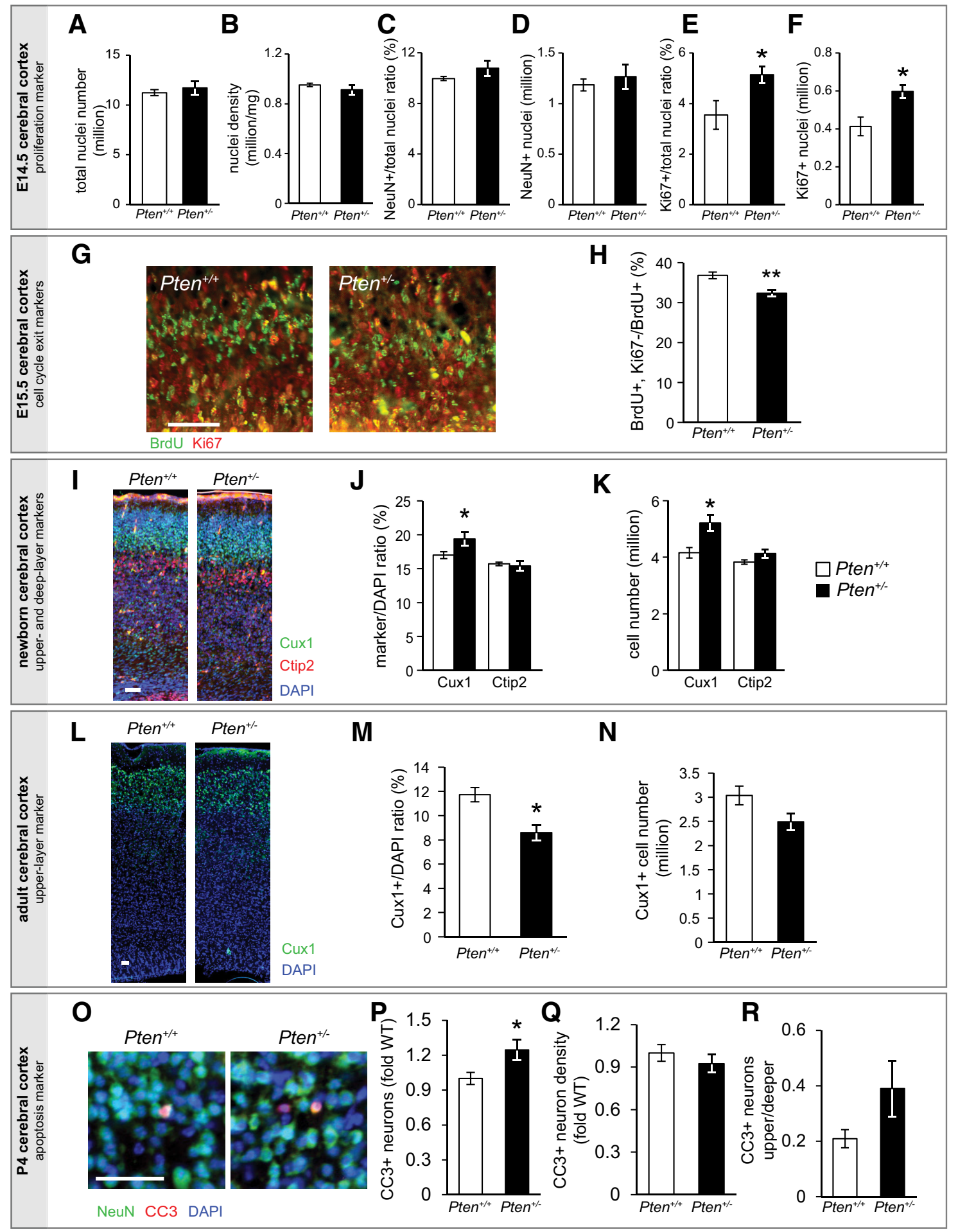

Figure 3. Markers of proliferation, lamination, and apoptosis in the cerebral cortex of germline Pten ${ }^{+/-}$mice. A-F, Data obtained using isotropicfractionator atE14.5.A, Total nucleinumber is not significantly changed within Pten ${ }^{+/-}$cerebral cortex. B, Nucleidensity within cerebral cortex. No significant differenceisobserved between WTand Pten ${ }^{+/-}$.C, Ratio of nucleipositivefor NeuN (neuronal marker, NeuN ${ }^{+}$) to total nuclei (DAPI ${ }^{+}$)

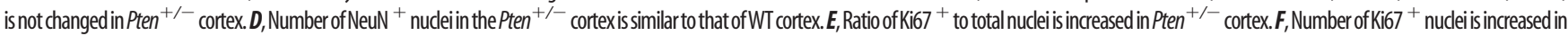
Pten $^{+/-}$cortex. G, Representative images showing BrdU (green, BrdU delivered at E14.5) and Ki67 (red) immunostaining in E15.5 cortex. H, Quantification of the ratio of BrdU ${ }^{+}$cells exiting cell cycle measured via immunohistochemistryatE15.5. Thereis a significantdecrease in the percentage of cells exiting the cell cycle (BrdU ${ }^{+}$, Ki6 $^{-}{ }^{-}$BrdU $\left.^{+}\right)$in Pten ${ }^{+/-}$cortex.Asinglepulse ofBrdU was injectedatE14.5.I, Representative images

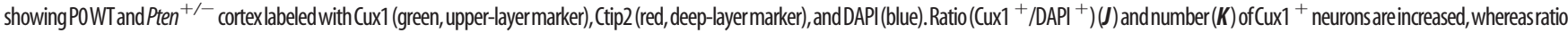
of Ctip2 ${ }^{+}$neurons is not changed in Pten ${ }^{+/-}$cortexatP0, as determined by isotropicfractionator. The total number of Ctip2 ${ }^{+}$neurons in Pten ${ }^{+/-}$cortex displays a trend toward an increase $(p=0.07) . \mathbf{L}$, Representative images showing adult WT and Pten ${ }^{+/-}$cortex labeled with Cux1 (green) and DAPI (blue). $M$, Ratio (Cux $1^{+} / \mathrm{DAPI}{ }^{+}$) of Cux ${ }^{+}$neurons is decreased, whereas $(\boldsymbol{N})$ the total number of Cux ${ }^{+}$neurons is not changed in $\mathrm{Pten}^{+/-}$cortex in adulthood, as determined by isotropic fractionator. $\mathbf{O}$, Images showing $\mathrm{CC} 3$ immunostaining within the cerebral cortex at P4. $\boldsymbol{P}$, Number of $\mathrm{CC} 3^{+}$neurons is increased, whereas (Q) the density of $\mathrm{CC} 3^{+}$ neuronsis not changed in Pten ${ }^{+/}$cortexatP4. Data are shown as the fold changefrom WT and are obtained through counting $C C^{+}$neurons in the cortex of images acquired after immunohistochemistry. $R$, The ratio of

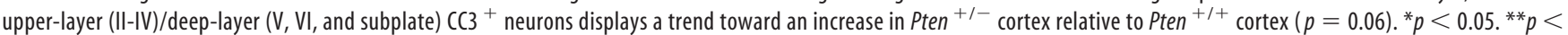
0.001. A-F, WT, $n=5 ;$ Pten $^{+/-}, n=5 . \boldsymbol{E}, \boldsymbol{P}, \boldsymbol{H}, \mathrm{WT}, n=3 ;$ Pten $^{+/-}, n=3 . \boldsymbol{J}, \boldsymbol{K}, \mathrm{WT}, n=10 ;$ Pten $^{+/-}, n=6 . \boldsymbol{M}, \boldsymbol{N}, \mathrm{WT}, n=4 ;$ Pten $^{+/-}, n=4$. Scale bars, $50 \mu \mathrm{m}$. Data are mean \pm SEM. 


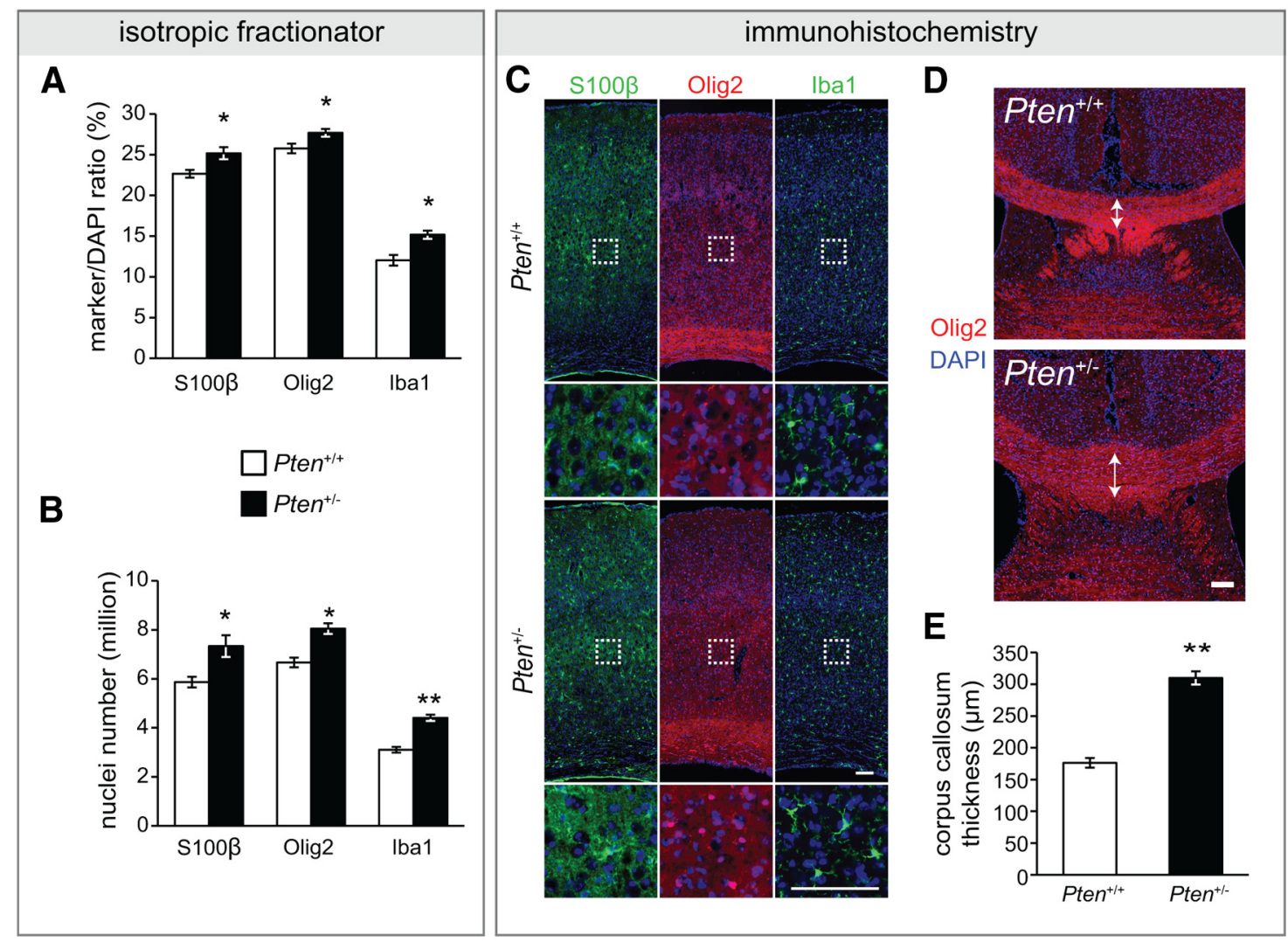

Figure 4. Increased number of glia in adult germline Pten $^{+/-}$cerebral cortex. A, Ratios of nuclei immunoreactive for $S 100 \beta$ (astrocyte marker), Olig2 (oligodendrocyte marker), and lba1 (microglia marker) to total nuclei $\left(\mathrm{DAPI}^{+}\right.$) are increased in adult Pten ${ }^{+/-}$cortex, as measured using isotropic fractionator. $\boldsymbol{B}$, Numbers of S100 $\beta^{+}, 0$ lig2 ${ }^{+}$, and lba ${ }^{+}$nuclei are increased in adult $\mathrm{Pten}^{+/-}$cortex. C, Representative images of adult WT and Pten ${ }^{+/-}$cortex immunostained with anti-S100 $\beta$ (green, left), anti-0lig2 (red, middle), or anti-lba1 (green, right), and DAPI (blue) showing that the signals of all three glial cell type markers are elevated in Pten ${ }^{+/-}$cortex. Scale bars, $100 \mu \mathrm{m}$. D, Representative images of adult WT and Pten ${ }^{+/-}$corpus callosum immunostained with anti-0lig2 (red) and DAPI (blue). Scale bars, $100 \mu \mathrm{m}$. E, The corpus callosum is thicker in adult Pten ${ }^{+/-}$mice than WT. ${ }^{*} p<0.05 .{ }^{* *} p<0.001 . \boldsymbol{A}, \boldsymbol{B}$, WT, $n=4 ;$ Pten ${ }^{+/-}, n=4 . \boldsymbol{C}-\boldsymbol{E}$, WT , $n=3 ;$ Pten $^{+/-}, n=3$. Data are mean \pm SEM.

Consistent with this possibility, in adult animals, we found a decrease in the Cux $1^{+} /$DAPI ratio, whereas the total Cux $1^{+}$ cell number was similar between WT and Pten ${ }^{+/-}$cortices (Fig. $3 L-N)$.

Because apoptosis is a mechanism by which excess neurons generated during embryonic neurogenesis are removed during postnatal development to arrive at a mature neuron population size (Naruse and Keino, 1995), we examined apoptosis marker cleaved caspase 3 (CC3) at postnatal day 4 . We found a significant increase in $\mathrm{CC}^{+}{ }^{+}$neurons within Pten ${ }^{+/-}$cortex (Fig. 3O-Q), even though $\mathrm{CC}^{+}{ }^{+}$neuronal density is not significantly changed. This result indicates that apoptosis is one mechanism by which excess neurons within Pten ${ }^{+/-}$cortex are removed. In addition, we also found a trend toward an increased ratio of upper-layer (II-IV)/deep-layer (V, VI, and subplate) $\mathrm{CC}^{+}$neurons in Pten ${ }^{+/-}$cortex $(p=0.06$; Fig. $3 R)$, suggesting that, along with a general increase in the number of apoptotic neurons throughout the Pten ${ }^{+1-}$ cortex, there may also be a relative increase in upper-layer neurons undergoing apoptosis in these animals.

\section{Excess glia in the cerebral cortex of adult germline Pten ${ }^{+/-}$ mice}

To determine the identity of excess non-neuronal cells in adulthood, we adapted the isotropic fractionator technique to allow for estimates of cells positive for the following glial cell type markers: Olig2 for oligodendrocytes (Yokoo et al., 2004), S100 $\beta$ for astrocytes (Bonaguidi et al., 2011), and Iba1 for microglia (Imai et al., 1996; Morgan et al., 2010). Importantly, all of these proteins have subcellular distributions that include the nucleus (Migheli et al., 1999; Ohsawa et al., 2000; Arnett et al., 2004). We found that both the ratio $\left(\mathrm{S} 100 \beta: t_{(6)}=2.85, p=0.029\right.$; Olig2: $t_{(6)}=$ $2.51, p=0.045$; Iba1: $t_{(6)}=3.82, p=0.009$; Fig. $\left.4 A\right)$ and the total number of nuclei positive for each of these glial markers $(S 100 \beta$ : $t_{(6)}=3.00, p=0.024$; Olig2: $t_{(6)}=4.61, p=0.004$; Iba1: $t_{(6)}=$ 7.46, $p<0.001$; Fig. $4 B$ ) were significantly increased in adult Pten $^{+/-}$cortex.

To confirm the presence of excess glia, adult brain sections were immunostained with the three markers listed above. We found that the density of all three glial markers (Fig. 4C), as well as GFAP, an additional marker for astrocytes (data not shown), was increased in Pten $^{+/-}$cortex. We speculated that this increase in glia might result in increased size of white matter tracts in Pten ${ }^{+/-}$brains, and we found that the thickness of the corpus callosum was significantly increased in adult Pten ${ }^{+/-}$ brains $\left(t_{(4)}=10.15, p<0.001\right.$; Fig. $\left.4 D, E\right)$. This is consistent with reports of alterations in the white matter and corpus callosum of individuals with heterozygous PTEN mutations (Frazier et al., 2014).

Markers of elevated $\boldsymbol{\beta}$-catenin activity in the developing cerebral cortex of newborn germline $\mathrm{Pten}^{+/-}$mice Pten functions as a negative regulator of cell growth through the PI3K-Akt-mTOR-S6 pathway (Fig. 5A). Pten also regulates pro- 
A
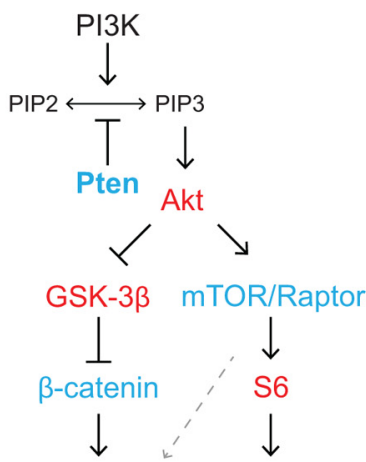

cell number cell size
B

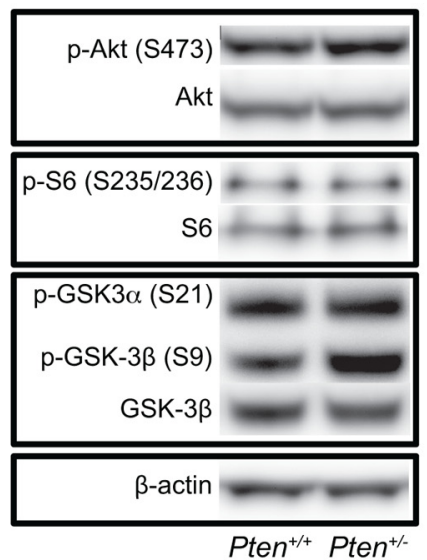

Pten $^{+/+}$Pten $^{+/}$

C
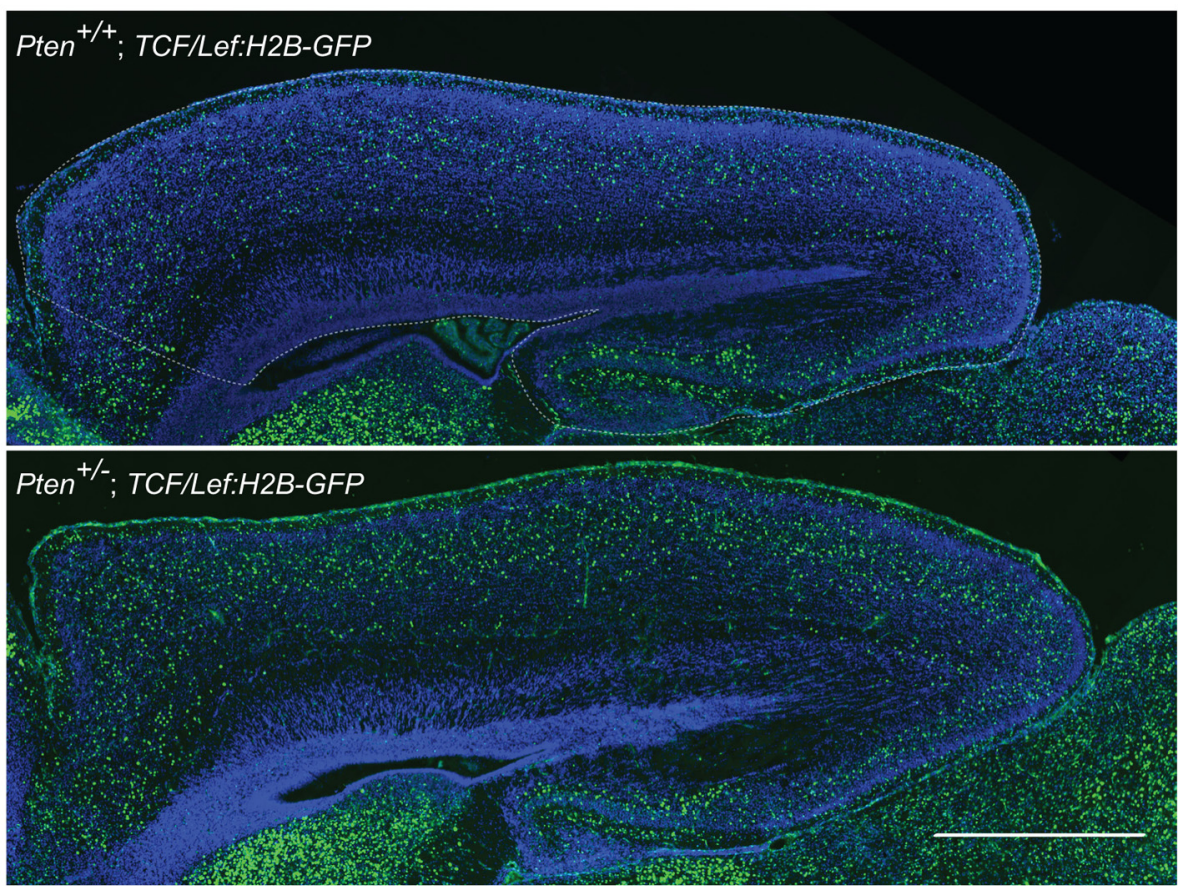

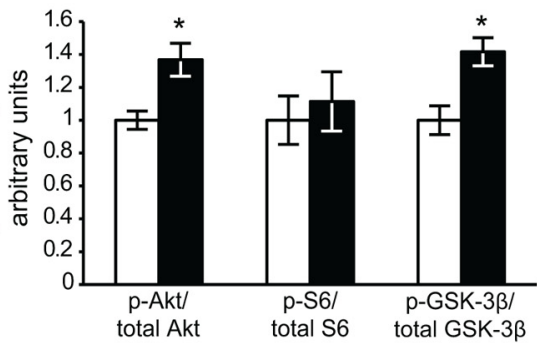

Pten $^{+/+}$

Pten $^{+-}$
$\mathbf{E}$

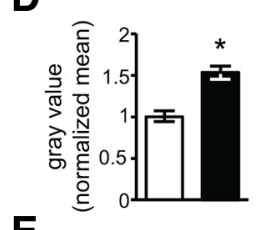

$\mathbf{F}$

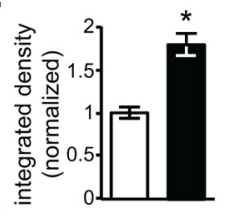

G

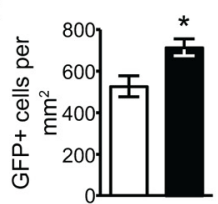

Figure 5. Markers of $\beta$-catenin activity are elevated in the cerebral cortex of germline Pten ${ }^{+/-}$mice at birth. $A$, Hypothetical model of Pten and downstream signaling pathways. In this highly simplified schema, Pten negatively regulates the PI3K-Akt pathway to control cell number through GSK-3 $\beta$ - $\beta$-catenin signaling and cell size through mTOR-S6 signaling. Red represents pathway components probed in this study by Western blot. Blue represents those tested by genetic manipulations. Dashed line connecting $\mathrm{mTOR} /$ Raptor/ $\$ 6$ signaling to cell number indicates that these processes have been linked in previous studies. B, p-Akt and p-GSK-3 $\beta$ are increased in Pten ${ }^{+/-}$cortex as determined by Western blot analysis. $n=5$ for both WT and Pten ${ }^{+/-}$. C $-\mathbf{G}$, Increased expression of a reporter (TCF/Lef:H2B-GFP) for $\beta$-catenin activity in Pten ${ }^{+/-}$cortex at PO. WT: $n=4$; Pten ${ }^{+/-}: n=3$. C, Representative images of WT (top) and Pten ${ }^{+/-}$(bottom) cortex showing reporter activity (nuclear-localized GFP) in green and DAPl in blue. Scale bar, $1 \mathrm{~mm}$. Density of GFP signal (D), total GFP signal (E), total number of GFP-positive cells $(\boldsymbol{F})$, and density of GFP-positive cells $(\boldsymbol{G})$ are increased in Pten $^{+/-}$cortex. $^{*} p<0.05$. Data are mean \pm SEM.

liferation through GSK-3 $\beta, \beta$-catenin, and cyclin D (Radu et al., 2003; Huang et al., 2007). To understand whether these pathways are dysregulated in $\mathrm{Pten}^{+/-}$cortex, we examined key readouts of these pathways. Western blot analysis of P0 cerebral cortex revealed a significant increase in the level of phospho-Akt (p-Akt; $\left.t_{(8)}=2.53, p<0.05\right)$ and phospho-GSK- $3 \beta$ (p-GSK-3 $\beta ; t_{(8)}=$ $2.95, p<0.05)$ in Pten $^{+/-}$mice, but we did not detect a significant change in levels of phospho-S6 (p-S6) at this stage (Fig. 5B).

Because we observed elevated p-GSK-3 $\beta$ in newborn $\mathrm{Pten}^{+/-}$cortex, and given that GSK- $3 \beta$ regulates $\beta$-catenin activity (Aberle et al., 1997; Clevers and Nusse, 2012), we hypothesized that Pten haploinsufficiency leads to increased $\beta$-catenin activity in the developing brain. To test this hypoth- esis, we crossed $\beta$-catenin reporter TCF/Lef:H2B-GFP (FerrerVaquer et al., 2010), which GFP labels the nuclei of cells that have undergone active $\beta$-catenin signaling, into a germline Pten $^{+1-}$ background. We then compared GFP signal between WT and Pten ${ }^{+1-}$ cortices at P0 (Fig. 5C). We found that there were significant increases in GFP mean signal $\left(t_{(5)}=-5.11\right.$, $p=0.004$; Fig. $5 D)$ and total signal $\left(t_{(5)}=-5.77, p=0.002\right.$; Fig. $5 E)$ in Pten $^{+/-}$cortex compared with WT cortex. In addition, the total number $\left(t_{(5)}=-3.07, p=0.028\right.$; Fig. $\left.5 F\right)$ and density of GFP ${ }^{+}$cells $\left(t_{(5)}=-2.79, p=0.038\right.$; Fig. $\left.5 G\right)$ were also increased in Pten $^{+-}$cortex at birth. Given the lag between $\beta$-catenin activity and reporter expression (FerrerVaquer et al., 2010), this likely reflects abnormally high levels of $\beta$-catenin signaling in the prenatal Pten $^{+/-}$brain. 
Pten conditional haploinsufficiency recapitulates cerebral

cortex overgrowth

Our results thus far demonstrate that the cerebral cortex of germline Pten ${ }^{+/-}$mice captures the overgrowth seen throughout the brains of these animals and that this phenotype coincides with increased $\beta$-catenin signaling in the developing cortex. To determine whether modulation of mTOR or $\beta$-catenin activity modifies Pten $^{+/-}$-induced cortical overgrowth, we wanted to isolate the effects of Pten mutations to the developing cerebral cortex. This would give greater control over cell type-specific effects of Pten mutations and would allow us to circumvent the potential problem of embryonic lethality. Homozygous germline loss-of-function mutations in Pten are lethal in early embryogenesis (Podsypanina et al., 1999); we predict that a second site genetic modifier that acts as a strong enhancer of germline Pten $^{+/-}$phenotypes may also be embryonic lethal.

To test whether conditional haploinsufficiency of Pten in the cerebral cortex is sufficient to induce cortex overgrowth, we recombined one copy of a floxed allele of Pten using Emx1-Cre. This driver is expressed in cortical neural progenitor cells and descendants, including pyramidal neurons, astrocytes, and oligodendrocytes, as well as in a subset of cells in the olfactory bulb (Gorski et al., 2002). Whole-brain mass of adult male Emx1$\mathrm{Cre}^{+}$; Pten ${ }^{\text {loxP/+}}$ mice was significantly higher than controls $\left(t_{(10)}=3.37, p=\right.$ $0.007)$, and upon dissection, cerebral cortex $\left(t_{(10)}=6.15, p<0.001\right)$ showed a significant increase in mass, whereas the mass of cerebellum, olfactory bulb, and remainder was similar to control mice (Fig. 6A). Emx1-Cre ; Pten $^{\text {loxP/+ }}$ female mice also exhibited similar overgrowth of the cortex (data not shown). Adult Emx1-Cre ${ }^{+}$Pten $^{\text {loxP/+ }}$ cortex also showed an increase in total cell number $\left(t_{(10)}=5.17, p<0.001\right.$; Fig. $\left.6 B\right)$, no significant change in cell density (Fig. $6 C, E$ ), and a decrease in $\mathrm{NeuN}^{+} / \mathrm{DAPI}^{+}$ratio $\left(t_{(10)}=3.92, p=0.003\right.$; Fig. $\left.6 D, E\right)$, confirming that Emx1-Cre ${ }^{+}$Pten ${ }^{\text {loxP/+ }}$ mice phenocopy germline Pten $^{+/-}$mice and thus are a useful model to isolate the effects of Pten haploinsufficiency to the cerebral cortex.

\section{Genetic reduction of Mtor does not suppress overgrowth in conditional Pten $^{+/-}$cerebral cortex}

Although our Western blot analysis of newborn Pten ${ }^{+/-}$cortex did not indicate a significant change in p-S6 levels (a readout for mTOR activity; Fig. $5 B$ ), there are likely spatial or temporal alterations in mTOR activity that may not be detected using this approach. Thus, we also wanted to test whether a genetic reduction of mTOR itself may modify Pten ${ }^{+/-}$-induced cortical overgrowth. We found that Emxl-Cre ${ }^{+} ; \mathrm{Pten}^{\text {loxP/+}} ; \mathrm{Mtor}^{\text {loxP/+ }}$ whole brain and cortex mass were not significantly different from that of Emx1-Cre ${ }^{+}$; ten $^{\text {loxP/+ }}$ mice, based on one-way ANOVA and post hoc tests (Fig. 7A). We also found that neither total number nor density of cortical cells significantly differed between these two groups (Fig. $7 B-D$ ). Given the ample evidence that suppressing mTOR complex 1 (mTORC1) activity can rescue brain overgrowth in conditional homozygous Pten mutants (for review, see Zhou and Parada, 2012), we also crossed a germline loss-offunction allele for Rptor (Guertin et al., 2006), which encodes the mTORC1 effector Raptor, into a germline Pten ${ }^{+/-}$background. Consistent with our previous results, we found that genetic reduction of Raptor did not modify cortical overgrowth caused by Pten haploinsufficiency (Fig. 7E-G).

\section{Genetic reduction of $\beta$-catenin suppresses overgrowth in}

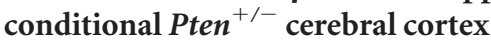

Because we found evidence for elevated $\beta$-catenin activity in Pten $^{+/-}$cortex (Fig. 5), we hypothesized that genetically reducing levels of $\beta$-catenin (encoded by the gene Ctnnb1) could suppress $P t e n^{+/-}$-induced brain overgrowth. Thus, we 
A

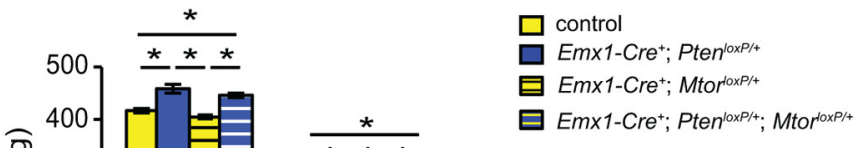

B

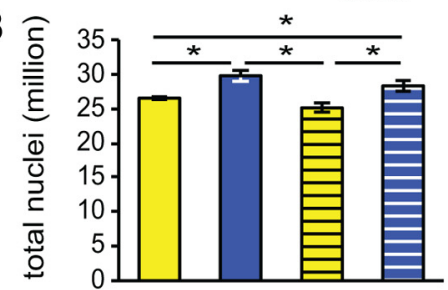

D

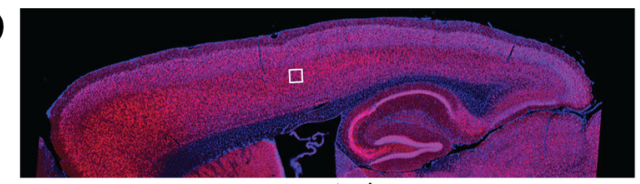

control

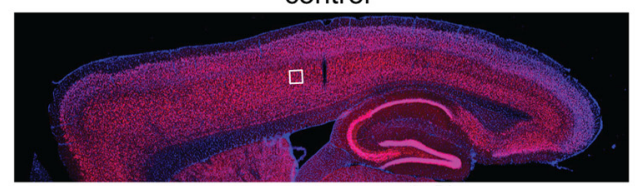

Emx1-Cre $;$ Pten $^{\text {loxP/+ }}$

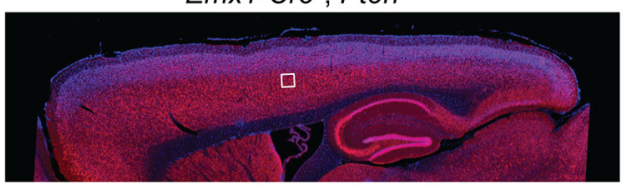

Emx1-Cre $;$ Mtor $^{\mathrm{IoxP} /+}$

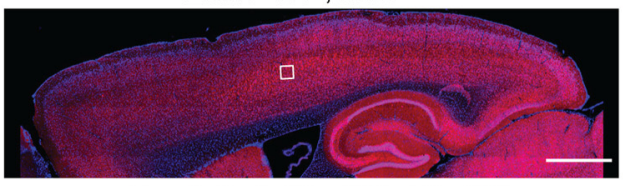

Emx1-Cre $;$ Pten $^{\text {loxP/+}} ;$ Mtor $^{\text {loxP/+ }}$
C
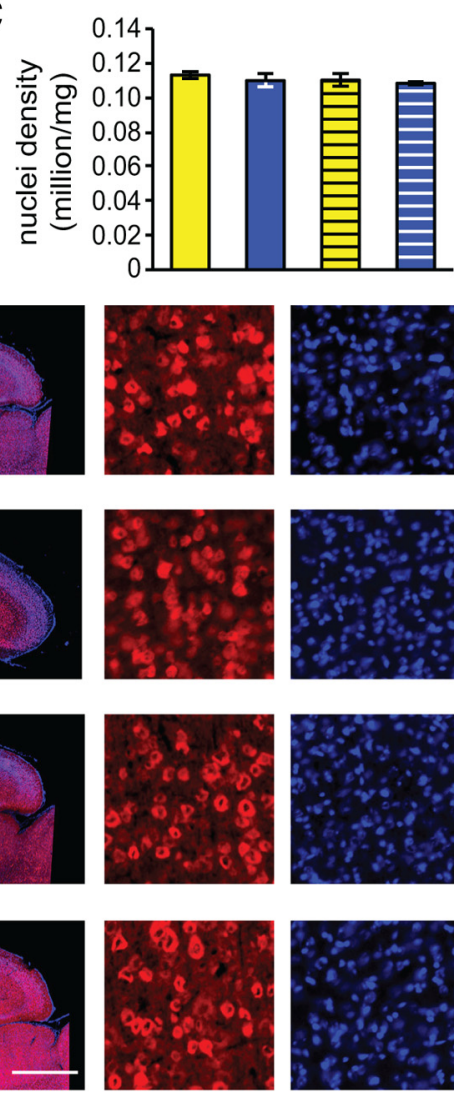

NeuN
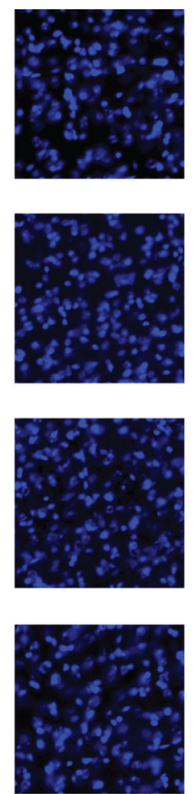

DAPI
E

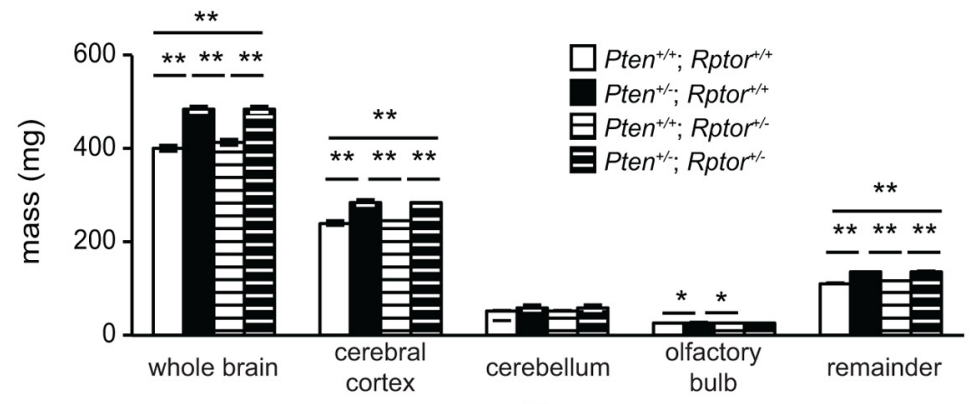

$\mathbf{F}$

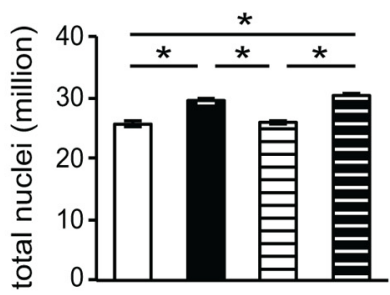

G

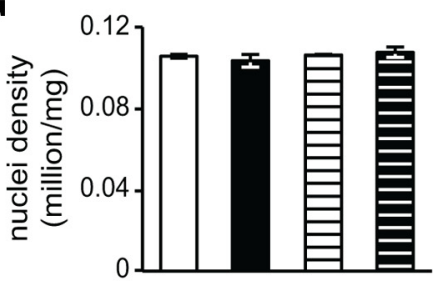

Figure 7. Genetic reduction of Mtor or Rptor does not modify overgrowth of Pten ${ }^{+/-}$cerebral cortex in adulthood. $A$, Whole

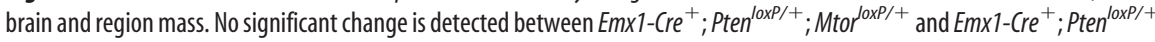
mice. $\boldsymbol{B}$, Total nuclei number in the cortex, measured using isotropic fractionator. No significant difference be-

generated Emxl-Cre ${ }^{+}$; Pten $^{\text {loxP/+ }}$; Ctnnb $1^{\text {loxP/+ }}$ mice and examined the cerebral cortex of these animals in adulthood. We found a significant effect of genotype on cortex mass $\left(F_{(3,17)}=\right.$ 45.33, $p<0.001)$, with post hoc tests indicating that the cortex of Emx1$\mathrm{Cre}^{+}$; Pten loxP/+$^{\text {lo }}$ Ctnnb1 $1^{\text {loxP/+ }}$ mice weighed significantly less than that of Emx1-Cre ${ }^{+} ;$Pten $^{\text {loxP/+ }}$ mice $(p=0.001)$ and more than that of control mice $(p<$ 0.001 ; Fig. $8 A$ ).

To determine whether conditional haploinsufficiency of Ctnnb1 suppresses cortex hyperplasia in adulthood, we measured the total number of cells in Emx1$\mathrm{Cre}^{+}$; Pten ${ }^{\text {loxP/+}} ;$ Ctnnbl ${ }^{\text {loxP/+}}$ cortex. There was a significant effect of genotype on cortical cell number $\left(F_{(3,17)}=18.82\right.$, $p<0.001)$, with post hoc tests indicating that Emx1-Cre ${ }^{+}$Pten $^{\text {loxP/+}} ; \mathrm{Ctnnb1}^{\text {loxP/+ }}$ cortex had significantly fewer cells than Emx $1-\mathrm{Cre}^{+} ;$Pten $^{\text {loxP/+ }}$ cortex $(p=0.018)$ and significantly more cells than control cortex $(p=0.013$; Fig. $8 B)$. Cortical cell density was unchanged across genotypes (Fig. 8C). Finally, we investigated whether Ctnnb1 conditional haploinsufficiency could reverse the decreased $\mathrm{NeuN}^{+} /$ $\mathrm{DAPI}^{+}$ratio seen in adult $\mathrm{Pten}^{+/-}$cortex. We found significant effects of genotype on $\mathrm{NeuN}^{+} / \mathrm{DAPI}^{+}$ratio $\left(F_{(3,17)}=21.83\right.$, $p<0.001)$ and $\mathrm{NeuN}^{-}$cells $\left(F_{(3,17)}=\right.$ $32.07, p<0.001$ ), with post hoc tests indicating that the decreased $\mathrm{NeuN}^{+}$/ $\mathrm{DAPI}^{+}$ratio seen in Emx1-Cre $e^{+/-}$; Pten $^{\text {loxP/+ }}$ cortex was suppressed in Emx1-Cre $e^{+} ;$Pten $^{\text {loxP/+}} ; \quad$ Ctnnbl $1^{\text {loxP/+ }}$ cortex $(p=0.036$; Fig. $8 D)$, due to a significant decrease in $\mathrm{NeuN}^{-}$cells $(p=0.001$; Fig. $8 F)$. The number of cortical $\mathrm{NeuN}^{+}$cells was similar among all four genotypes (Fig. 8E). Representative cortex images with stained with NeuN and DAPI are shown in Figure $8 G$. Our results indicate that genetic

$\leftarrow$

tween $\mathrm{Emxl}^{-\mathrm{Cre}^{+}} ; \mathrm{Pten}^{\mathrm{IOxP} /+} ; \mathrm{Mtor}^{\mathrm{O} \times \mathrm{PP} /+}$ and Emx1-Cre ${ }^{+}$. Pten ${ }^{\text {loxP/+ }}$ cortex. $C$, Nuclei density is similar across all genotypes. Control: $n=5 ;$ Emx1-Cre $^{+} ;$Pten $^{\text {IoxP/+ }}: n=4 ;$ Emx1-

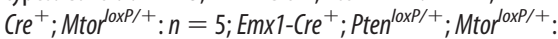
$n=3$. D. Representative images of immunostained control, $\mathrm{Emx}^{+}-\mathrm{Cre}^{+} ; \mathrm{Pten}^{\mathrm{IoxP} /+}, \mathrm{Em} 1-\mathrm{Cre}^{+} ; \mathrm{Mtor}^{\mathrm{IoxP} /+}$, and Emx1$\mathrm{Cre}^{+} ;$Pten $^{\text {loxP/+ }} ; \mathrm{Mtor}^{\text {loxP/++}}$ cortices (left panels), with magnified insets on the right. Red represents NeuN. Blue represents DAPI. Scale bar, $1 \mathrm{~mm}$. E-G, Germline Rptor haploinsufficiency does not modify overgrowth or hyperplasia in cerebral cortex of germline Pten ${ }^{+/-}$mice. $\boldsymbol{E}$, Brain and brain region mass, $(\boldsymbol{F})$ total nuclei number in the cortex, and $(\boldsymbol{G})$ nuclei density are similar across all genotypes. $n=4$ for all genotypes. All mice included in this figure are adults. ${ }^{*} p<$ 0.05 . ${ }^{* *} p<0.001$. Data are mean \pm SEM. 
reduction of $\beta$-catenin acts as a suppressor of the cortex overgrowth, hyperplasia, and altered allocation of neuronal/ non-neuronal cells caused by Pten haploinsufficiency.

\section{Comparison of heterozygous versus homozygous conditional Pten mutations on cell number and density in the newborn cerebral cortex}

Since previous reports have demonstrated that homozygous Pten mutations lead to cellular hypertrophy (Goberdhan et al., 1999; Backman et al., 2001; Groszer et al., 2001; Kwon et al., 2001; Fraser et al., 2004; Kazdoba et al., 2012), we hypothesized that heterozygous and homozygous Pten mutations may have differential effects on cell density in the developing brain. We first examined brain mass in $\mathrm{Em} \times 1-\mathrm{Cre}^{+}$; $\mathrm{Pten}^{\text {loxP/+}}$ and Emx1-Cre ${ }^{+}$; Pten ${ }^{\text {loxP/loxP }}$ mice at P0. We did not examine adult animals because Emxl-Cre ${ }^{+}$; Pten ${ }^{\text {loxP/loxP }}$ mice were not viable after P10. One-way ANOVA revealed significant effects of genotype on brain mass $\left(F_{(2,14)}=29.55, p<\right.$ $0.001)$ and cortex mass $\left(F_{(2,14)}=65.35\right.$, $p<0.001)$. Planned comparisons showed that brain mass of both Emx1-Cre ${ }^{+}$; $\mathrm{Pten}^{\text {loxP/+}}$ and Emx1-Cre ${ }^{+}$Pten PtoxP/loxP $^{\text {Em }}$ mice was significantly increased relative to control mice $\left(\right.$ Emxl-Cre ${ }^{+} ;$Pten $^{\text {loxP/+ }}: t_{(10)}$ $=4.03, p=0.002 ; \quad E m x 1-\mathrm{Cr}^{+}$; Pten ${ }^{\text {loxP/loxP }}: t_{(10)}=6.87, p<0.001$; Fig. $9 A)$. This increase was restricted to the cortex $\left(E m x 1-\mathrm{Cre}^{+} ;\right.$Pten $^{\text {loxP/+}}: t_{(10)}=$ 4.26, $p=0.002$; Emx1-Cre ${ }^{+}$Pten $^{\text {loxP/loxP }}$ : $t_{(10)}=9.40, p<0.001$; Fig. 9A). The Emx1-Cre ${ }^{+}$Pten $^{\text {loxP/loxP }}$ cortex was noticeably larger than Emxl-Cre ${ }^{+}$; Pten ${ }^{\text {loxP/+ }}$ and control cortices, with Emx1-Cre ${ }^{+}$; Pten ${ }^{\operatorname{loxP} / l o x P}$ having an average cortex mass almost double that of control mice. Representative sagittal brain sections show a massive increase in cortex size in Emx1$\mathrm{Cre}^{+}$; Pten ${ }^{\text {loxP/loxP }}$ mice compared with Emx1-Cre ${ }^{+}$Pten $^{\text {loxP/+ }}$ and control brains (Fig. 9E).

These results indicate that cortex size does not increase linearly with decreased Pten dosage. To determine the relative contributions of altered cell number and density to the dramatic increase in cortical growth caused by homozygous Pten mutations, and to compare this to the effects of heterozygous Pten mutations, we applied isotropic fractionator to the cerebral cortex of P0 Emx1-Cre ${ }^{+}$Pten ${ }^{\text {loxP/loxP }}$, Emx1-Cre ${ }^{+}$Pten $^{\text {loxP/+}}$, and control animals. One-way ANOVA indicated significant effects of genotype on total cell number $\left(F_{(2,14)}=11.21, p=0.001\right)$, cell density $\left(F_{(2,14)}=35.68, p<0.001\right)$, and
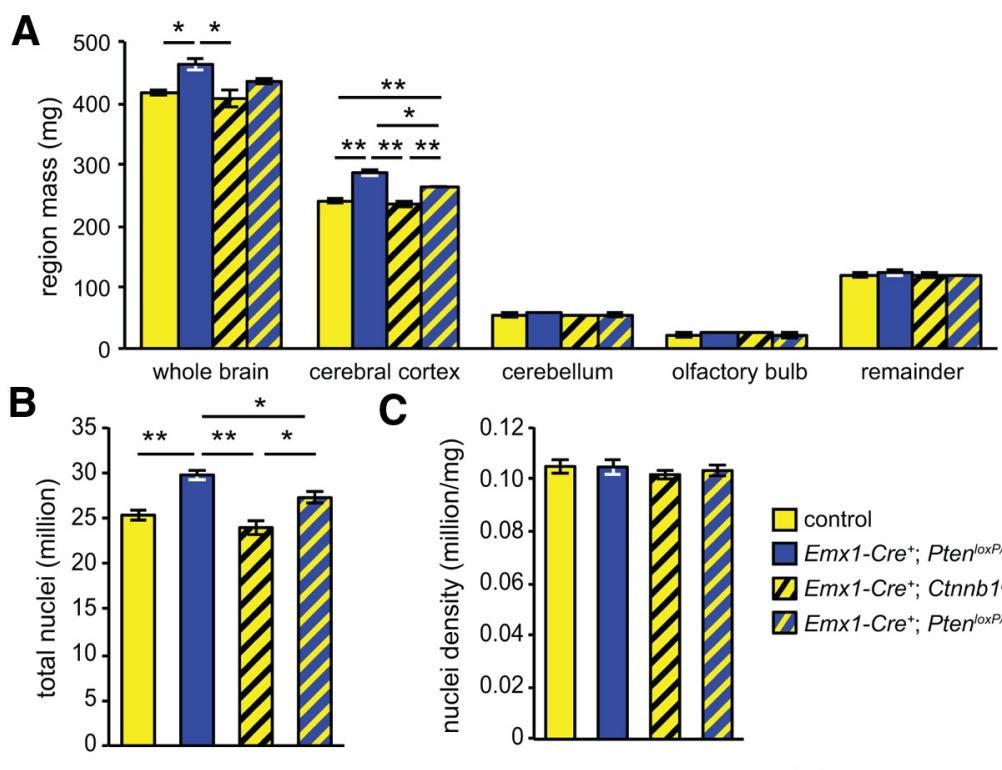

C
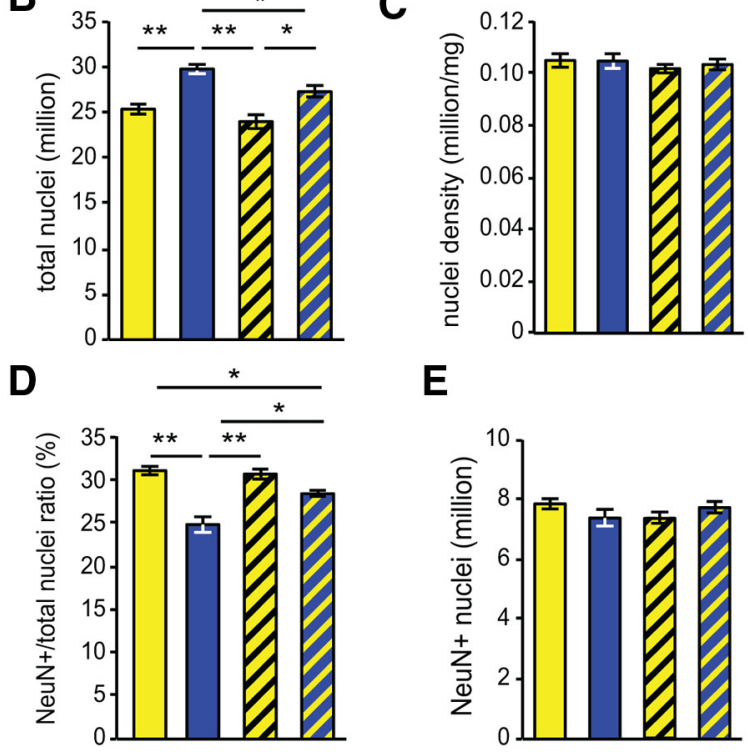

E
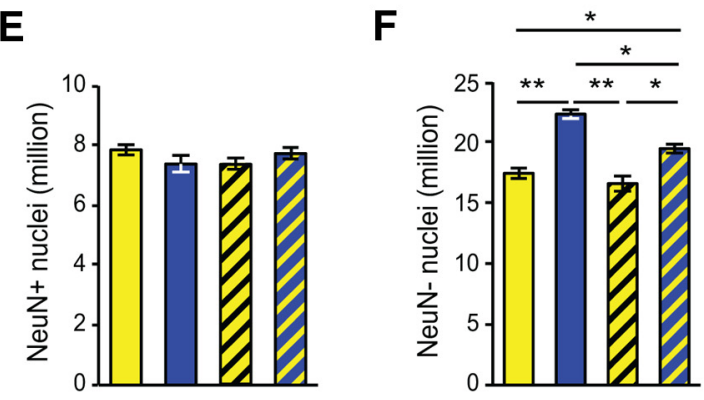

G
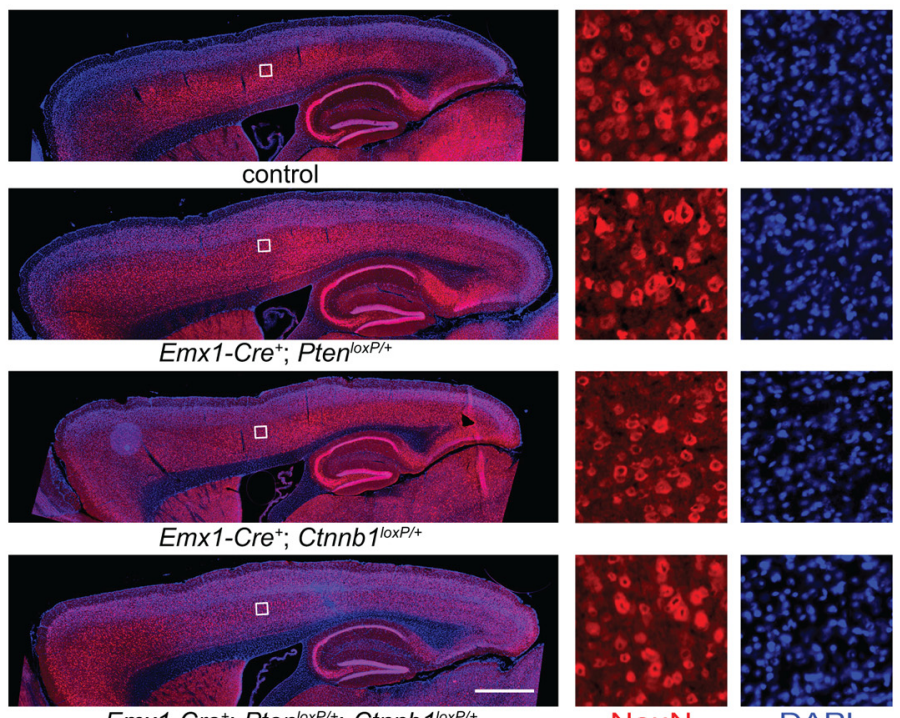

NeuN

DAPI

Figure 8. Genetic reduction of $\beta$-catenin suppresses overgrowth of conditional Pten ${ }^{+/-}$cerebral cortex in adulthood. $\boldsymbol{A}$, Brain

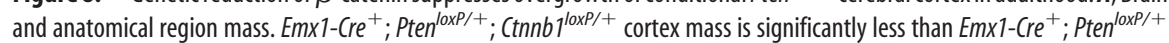

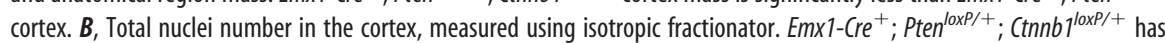
significantly fewer than $\mathrm{Emx1}^{-} \mathrm{Cr} \mathrm{e}^{+} ; \mathrm{Pten}^{\mathrm{loxP} /+}$ cortex. C, Nuclei density in the cortex is similar among all groups. D, Ratio of nuclei positive for NeuN (neuronal marker) to total nuclei $\left(\mathrm{DAPI}^{+}\right)$. The ratio in $E m \times 1-\mathrm{Cre}^{+} ; \mathrm{Pten}^{\text {loxP/+}} ;$ (tnnb $1^{\text {loxP/+ }}$ cortex is significantly higher than that of Emx1-Cre ${ }^{+}$Pten ${ }^{10 x P /+}$ cortex. $E$, Number of $\mathrm{NeuN}^{+}$nuclei in the cortex is similar across all genotypes.

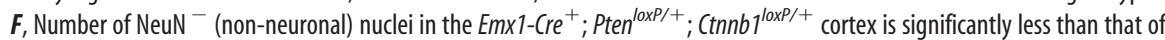

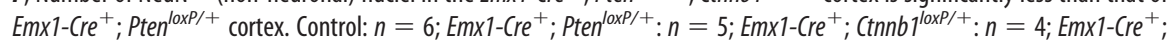
Pten ${ }^{10 \times P /+} ; C \operatorname{Ctnnb} 1^{10 \times P /+}: n=6$. All mice included in this figure are adults. ${ }^{*} p<0.05 .{ }^{* *} p<0.001$. Data are mean \pm SEM. $G$,

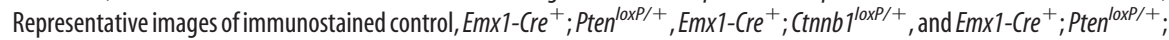
Ctnnb $7^{\text {loxP/+ }}$ cortices (left panels), with magnified insets on the right. Red represents NeuN. Blue represents DAPI. Scale bar, $1 \mathrm{~mm}$. 
A

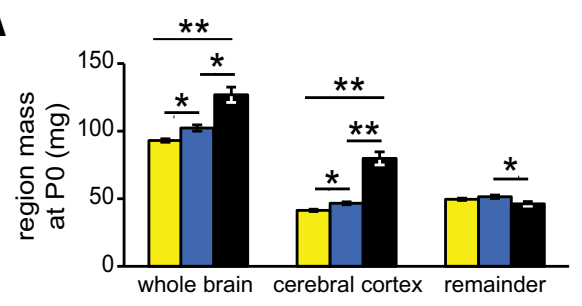

B

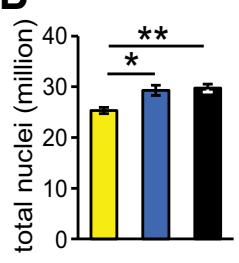

C

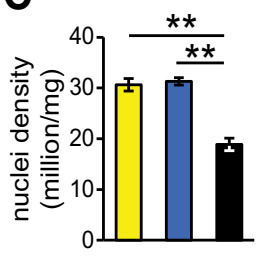

D

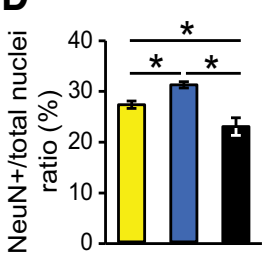

E

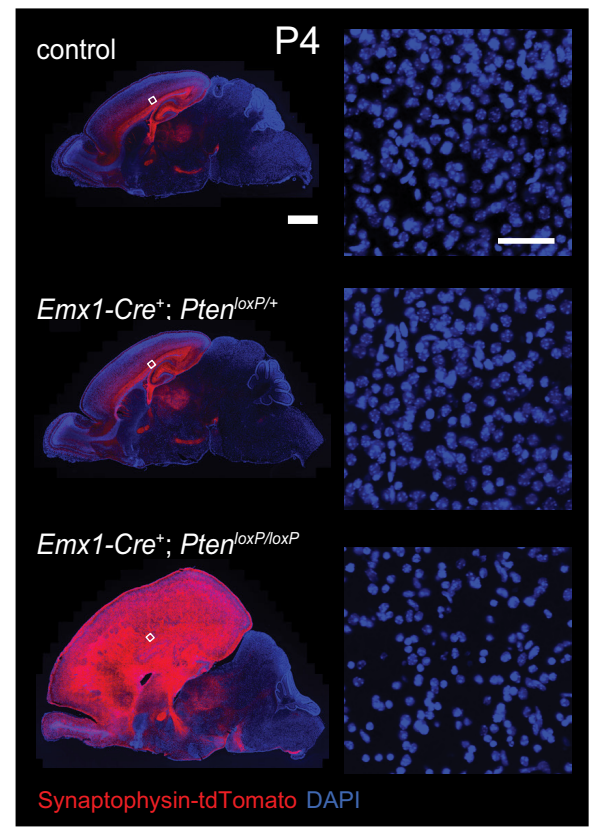

$\mathbf{F}$

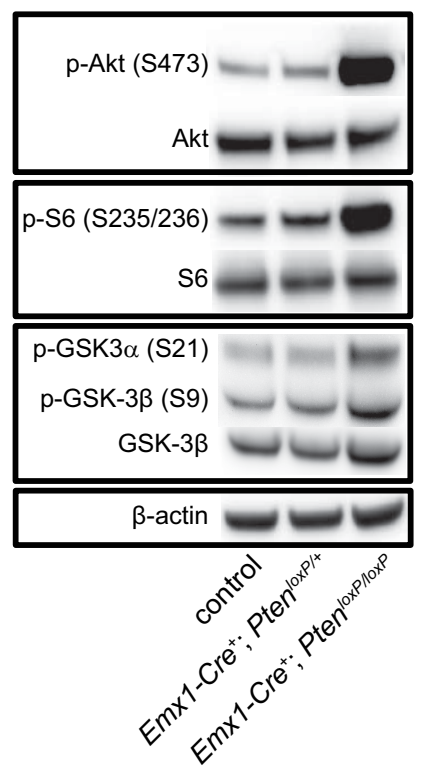

$\square$ control

$\square$ Emx1-Cre $;$ Pten ${ }^{10 \times P /+}$

Emx1-Cre ${ }^{+}$Pten ${ }^{\text {loxP/loxP }}$

G

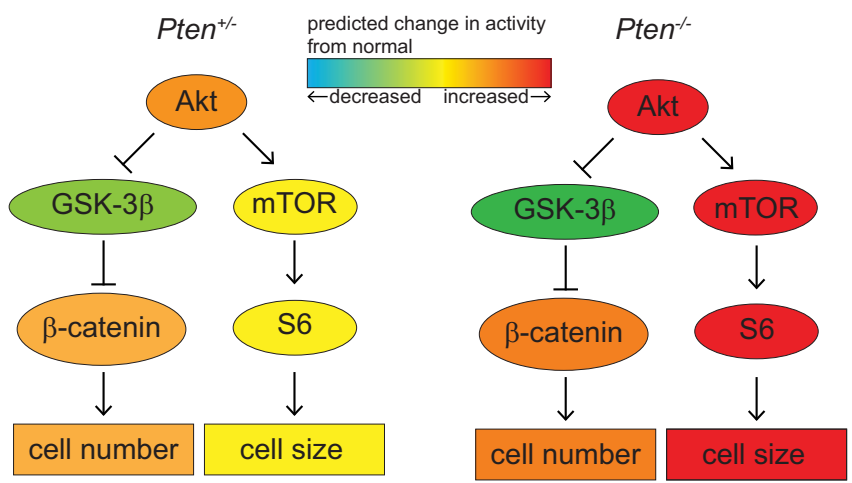

Figure 9. Effects of homozygous versus heterozygous conditional Pten mutations on cell number, density, neuronal ratio, and downstream signaling in the newborn cerebral cortex. $\boldsymbol{A}-\boldsymbol{D}$, Conditional deletion of Pten in the cortex leads to cortex overgrowth, increased cell number, and altered neuronal ratio at postnatal day $0(P 0)$. Control: $n=7 ; E m x 1-C r e{ }^{+} ; P$ ten ${ }^{\text {loxP } /+}: n=5$; Emx $1-C r e^{+} ;$Pten ${ }^{\text {IoxP } / / \text { loxP }}: n=5$. A, Brain and anatomical region mass. Pten dosage has nonlinear effects on whole brain, cortex, and remainder mass. $\boldsymbol{B}$, Total nuclei number is increased in $E_{\text {Emx1-Cre }}^{+} ;$Pten $^{\text {loxP/+ }}$ and Emx1-Cre ${ }^{+} ;$Pten ${ }^{\text {loxP/loxP }}$ cortex compared with control, as measured using isotropic fractionator. No significant difference was observed between Emx1-Cre ${ }^{+} ;$Pten ${ }^{\text {IoxP/+ }}$ and $E m \times 1-C r e^{+} ;$Pten $^{\text {IoxP/loxP }}$ cortices. C, Nuclei density is significantly reduced in Emx1-Cre ${ }^{+} ;$Pten ${ }^{\text {IoxP/loxP }}$ cortex compared with control or Emx1-Cre ${ }^{+} ;$Pten ${ }^{\text {IoxP/+ }}$. No significant difference was

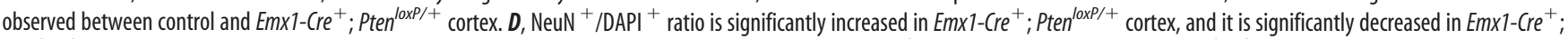
Pten $^{\text {loxP/loxP }}$ cortex, compared with control. E, Representative sagittal sections of control (top), Emx1-Cre ${ }^{+} ;$Pten ${ }^{\text {IoxP/+ }}$ (middle), and Emx1-Cre ${ }^{+}$; Pten ${ }^{\text {IoxP/loxP }}$ (bottom) brains at P4. Right panels, Magnified images of the insets on the left panels. A floxed synaptophysin:tdTomato reporter (Ai34) is shown in red to visualize the pattern of Emx1-Cre-mediated recombination; blue represents

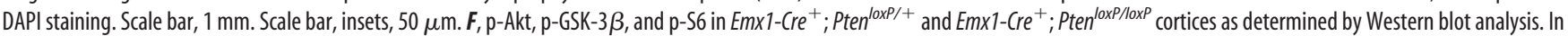

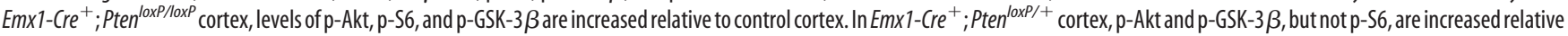
to controls. $n=5$ for control, Emx1-Cre ${ }^{+}$; Pten IoxP/+ , and Emx1-Cre ${ }^{+}$; Pten ${ }^{\text {IoxP/loxP }} .{ }^{*} p<0.05 .{ }^{* *} p<0.001$. Data are mean \pm SEM. $\mathbf{G}$, Simplified model of effects of homozygous versus heterozygous Pten mutations on mTOR-S6 signaling and cellular growth in the developing cortex.

$\mathrm{NeuN}^{+} / \mathrm{DAPI}^{+}$ratio $\left(F_{(2,14)}=13.54, p=0.001\right.$; Fig. $\left.9 B-D\right)$. Planned comparisons revealed that the total number of cells in Emxl-Cre ${ }^{+}$; Pten ${ }^{\text {loxP/+ }}$ cortex was significantly higher than that of control cortex $\left(t_{(10)}=3.62, p=0.005\right.$; Fig. 9B). Interestingly, although we also found increases in total cell number in Emx1$\mathrm{Cre}^{+} ;$Pten $^{\text {loxP } / \text { loxP }}$ cortex compared with control $\left(t_{(10)}=4.69, p<\right.$ 0.001 ; Fig. $9 B$ ), there was no significant difference in total cell number between Emx1-Cre ${ }^{+}$Pten $^{\text {loxP/+ }}$ and Emx1-Cre ${ }^{+}$; Pten- 
loxP/loxP cortices. Consistent with the large increase in mass and relatively small increase in cell number, the cell density was significantly lower in the Emx1-Cre ${ }^{+}$; Pten ${ }^{\text {loxP/loxP }}$ cortex than the control $\left(t_{(10)}=6.69, p<0.001\right)$ and Emx1-Cre ${ }^{+} ;$Pten $^{\text {loxP/+ }}$ cortices $\left(t_{(8)}=8.76, p<0.001\right.$; Fig. $\left.9 C\right)$. We also found that the $\mathrm{NeuN}^{+} / \mathrm{DAPI}^{+}$ratio was significantly decreased in Emx1-Cre ${ }^{+}$; $P_{\text {ten }}^{\text {loxP/loxP }}$ cortex compared with that of controls $\left(t_{(10)}=2.62\right.$, $p=0.025$; Fig. $9 D)$, in contrast to the significantly increased $\mathrm{NeuN}^{+} / \mathrm{DAPI}^{+}$ratio in Emx1-Cre ${ }^{+}$; Pten ${ }^{\text {loxP/+}}$ cortex $\left(t_{(10)}=\right.$ $3.99, p=0.003$; Fig. 9D). These results suggest that Pten homozygous versus heterozygous mutations differentially impact cell density. This also gave us confidence that measurement of cell density via isotropic fractionator is capable of detecting the cellular hypertrophy that is well associated with homozygous mutations in Pten.

This nonlinear change in cortex mass, cell number, and neuronal/non-neuronal cell type allocation as a result of homozygous versus heterozygous Pten mutations led us to hypothesize that downstream molecular pathways may also be differentially impacted. We therefore examined p-Akt, p-S6, and p-GSK-3 $\beta$ levels via Western blot. One-way ANOVA revealed a significant effect of genotype on levels of p-Akt $\left(F_{(2,12)}=21.58\right.$, $p<0.001)$, p-S6 $\left(F_{(2,15)}=24.82, p<0.001\right)$, and p-GSK-3 $\beta$ $\left(F_{(2,12)}=9.69, p=0.003\right)$. Planned comparisons showed that levels of p-Akt $\left(t_{(8)}=4.76, p=0.008\right), \mathrm{p}-\mathrm{S} 6\left(t_{(5)}=5.02, p=\right.$ $0.002)$, and p-GSK-3 $\beta\left(t_{(5)}=3.54, p=0.004\right)$ were significantly increased in Emxl-Cre ${ }^{+}$; $\mathrm{Pten}^{\text {loxP/loxP }}$ cortex relative to control, and that p-Akt $\left(t_{(8)}=2.32, p=0.016\right)$ and p-GSK-3 $\beta$ $\left(t_{(8)}=2.34, p=0.046\right)$, but not p-S6, were increased in Emx1$\mathrm{Cre}^{+}$; Pten ${ }^{\text {loxP/+}}$ cortex relative to control (Fig. 9F). Together, these data suggest that Pten gene dosage has nonlinear effects on downstream molecular pathways (Fig. 9G), with homozygous Pten mutations resulting in a robust hyperactivation of mTOR-S6 signaling in the newborn cerebral cortex.

\section{Discussion}

The brains of germline Pten ${ }^{+/-}$mice are overgrown from birth, with the magnitude of overgrowth showing a dynamic pattern through postnatal development

Heterozygous mutations in PTEN cause macrocephaly and increase risk for ASD (Butler et al., 2005; Buxbaum et al., 2007; Varga et al., 2009; McBride et al., 2010). MRI suggests that there may be a developmental trajectory to the effects of PTEN mutations on brain structure (Frazier et al., 2014). The relative rarity of PTEN mutations within the population of individuals with ASD and scarcity of postmortem brain samples, together with heterogeneity in genetic background among individuals with PTEN mutations, mean that animal models can be a valuable complement to these studies. Our use of isogenic Pten haploinsufficient mice in the present study allowed us to assess the trajectory of brain overgrowth caused by heterozygous Pten mutations and elucidate underlying cellular and molecular mechanisms, as discussed below.

\section{Overgrowth of the Pten ${ }^{+/-}$cortex coincides with excess neurons at birth, excess glia in adulthood}

Studies of individuals with ASD and macrocephaly have revealed overgrowth of the cerebral cortex in early childhood (Carper et al., 2002; Carper and Courchesne, 2005). Examination of postmortem samples from a group of children with ASD and macrocephaly indicates that hyperplasia may be a cause for brain overgrowth, with increased neuron number in prefrontal cortex and no change in neuron size or glia number (Courchesne et al.,
2011). Genes regulating the cell cycle have also been reported as enriched in postmortem brains of individuals with ASD (Chow et al., 2012). MRI has revealed alterations in gray and white matter volumes in individuals with ASD (Hazlett et al., 2005; Wassink et al., 2007; Schumann et al., 2010), and those with PTEN mutations show significantly increased white matter compared with individuals with idiopathic ASD or healthy controls (Frazier et al., 2014).

Our data show that overgrowth of the $\mathrm{Pten}^{+/-}$brain coincides with cortical hyperplasia, with excess neurons at birth and excess cortical glia and thickening of the corpus callosum in adulthood. We also find that the magnitude of brain overgrowth in $\mathrm{Pten}^{+/-}$ animals is dynamic over the course of development (Fig. 1B). Thus, it is worth considering the normal trajectory of neurogenesis and gliogenesis in the context of these observations. During cortical development, the timing of neurogenesis is largely prenatal, whereas gliogenesis is largely postnatal (Kriegstein and Alvarez-Buylla, 2009). The scale of the mature cortical neuronal population is influenced by a process of overproduction of neurons during embryonic neurogenesis, followed by an elimination of excess neurons by apoptosis during postnatal development (Naruse and Keino, 1995).

Pten and downstream PI3K-Akt signaling are associated with cell cycle regulation (Diao and Chen, 2007) and apoptosis (Chung and Eng, 2005), which are two cellular functions relevant for the control of cell number in the developing brain. Mutations in Pten have been reported to influence cell number in a variety of contexts, particularly in tumorigenesis (Li et al., 1997; Teng et al., 1997; Duerr et al., 1998). In the developing nervous system, conditional knock-out of Pten in neural progenitor cells leads to increased proliferation, as well as altered apoptosis (Groszer et al., 2001). Likewise, Pten conditional deletion in astrocyte precursors leads to increased proliferation (Fraser et al., 2004) and cultured Pten $^{+/-}$SVZ precursor cells proliferate at a higher rate than WT cells (Li et al., 2002).

Consistent with these cellular functions of Pten, we find more proliferating cells during embryonic neurogenesis, excess neurons at birth but not adulthood, more cells undergoing apoptosis during early postnatal development, and excess glia in adulthood in the Pten ${ }^{+/-}$cortex. These observations raise the intriguing possibility that Pten haploinsufficiency leads to sequential overproduction of neurons and glia, with a correction of excess neurons (e.g., via apoptosis), but not glia, occurring during postnatal development (Fig. 10). This may help explain the relatively small difference in brain mass between $\mathrm{Pten}^{+/-}$and WT at P4 and P7 (Fig. 1B).

It remains to be determined whether the excess neurons and glia seen in mutant animals reflect a cell-autonomous role for Pten in both neurogenesis and gliogenesis, or whether excess neurogenesis and subsequent apoptosis caused by Pten mutations may trigger an overproduction of glia (e.g., to remove cellular debris via phagocytosis). Future work will also investigate how the development of neural circuitry underlying ASD-relevant behaviors is impacted by sequential overproduction and trimming of neurons during corticogenesis, and by overproduction of glia during postnatal development. Relevant to this, it has been reported that overproduction of upper-layer cortical neurons, generated by pharmacological modulation of tankyrase/Axin signaling during embryonic neurogenesis, is associated with altered excitatory inhibitory balance and ASD-relevant behavioral phenotypes (Fang et al., 2014). Elevated markers of glia, including astrocytes and microglia, and neuroinflammation have been reported in the brains of ASD patients (Vargas et al., 2005; Suzuki et 


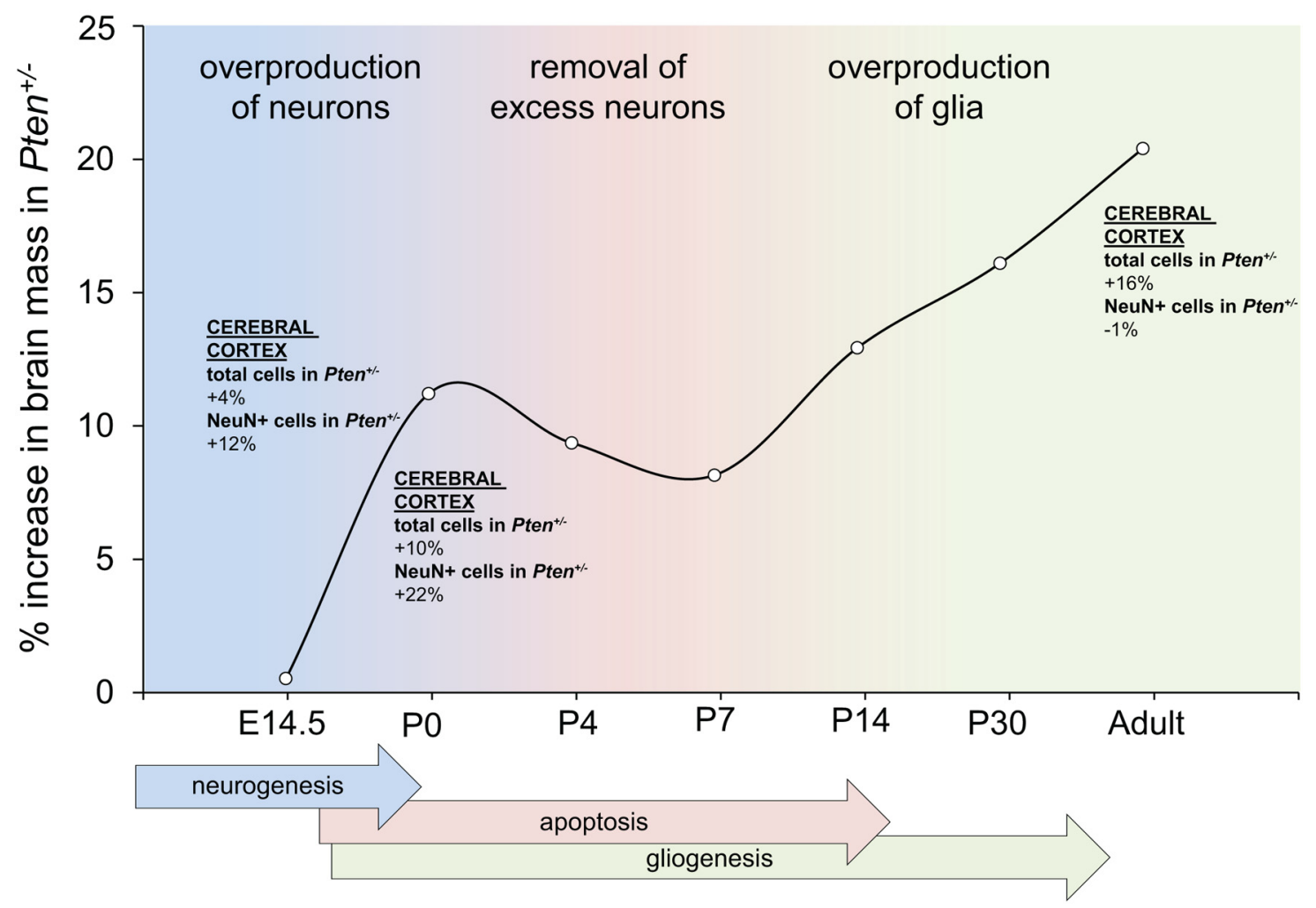

Figure 10. Model of the impact of Pten haploinsufficiency on the trajectory of corticogenesis. In this model, Pten haploinsufficiency leads to an exaggeration of the normal processes of neurogenesis, neuronal apoptosis, and gliogenesis that occur during cerebral cortical development. During embryonic neurogenesis, excess neurons are produced throughout the cortex, with a relative increase in upper layers. Apoptosis during early postnatal life removes excess neurons, and excess glia are produced during postnatal gliogenesis. These cellular events may help explain why the magnitude of overgrowth in the Pten ${ }^{+/}$brain is dynamic over development.

al., 2013; Edmonson et al., 2014). Astrocytes and microglia are involved in brain development processes potentially relevant to ASD pathogenesis, including synaptic pruning and plasticity (Zeidán-Chuliá et al., 2014).

Pten $^{+/-}$cortex shows elevated $\beta$-catenin signaling at birth, and genetic reduction of $\boldsymbol{\beta}$-catenin suppresses cortical overgrowth

There is evidence that Pten regulates $\beta$-catenin activity though Akt and GSK-3 $\beta$ in the context of cancer biology (Stambolic, 2002). However, a connection between Pten and $\beta$-catenin has not been established in the developing nervous system. In our study, we provide the first evidence of a genetic interaction between Pten and Ctnnb1, two factors linked with ASD and extreme variations in head circumference, in regulating growth in the developing brain via control of cell number, thus placing these in a common pathway.

Our findings that $\beta$-catenin signaling is elevated in the newborn $\mathrm{Pten}^{+/-}$cortex and that genetic reduction of $\beta$-catenin can suppress Pten $^{+/-}$-induced cortical overgrowth have implications for understanding the genetic landscape of autism. Extreme variations in head circumference in individuals with ASD are associated with de novo mutations in PTEN (macrocephaly), as well as in components of the Wnt- $\beta$-catenin pathway including CTNNB1 (microcephaly) and CHD8 (macrocephaly) (O'Roak et al., 2012; Stessman et al., 2014). In addition, mutations in CTNNB1 have been found to cause microcephaly and intellectual disability (de Ligt et al., 2012; Dubruc et al., 2014). Our present results inform these clinical genetic findings and indicate that Pten and $\beta$-catenin signaling act in a balance to regulate normal brain growth trajectory via control of cell number, and that disruption of this balance can lead to abnormal patterns of brain growth. Considering that CHD8 binds $\beta$-catenin and negatively regulates transcription of $\beta$-catenin target genes (Thompson et al., 2008), it would appear logical to predict that $\mathrm{CHD} 8$ also participates in this signaling network. It is possible that a similar mechanism might also be acting in other neurodevelopmental disorders that feature altered brain growth in subgroups of individuals, such as intellectual disability.

The focus of this study is on the trajectory and mechanisms of abnormal brain growth, with behavioral testing being beyond the scope of the present study. Future experiments will test whether ASD-relevant behaviors are modified in Pten haploinsufficient mice where cortical overgrowth and hyperplasia have been suppressed by reducing $\beta$-catenin activity. This will allow us to explore whether there is a causal relationship between hyperplasia and behavioral symptoms of ASD, and whether interventions targeting the $\mathrm{Wnt} / \beta$-catenin signaling system might be a complement to therapies that target mTOR signaling in individuals with ASD and macrocephaly.

\section{Homozygous versus heterozygous Pten mutations} differentially impact cell density and mTOR-S6 activity in the newborn cortex

Similar to our findings in germline Pten haploinsufficient mice, we find that conditional haploinsufficiency for Pten in the developing cortex leads to an increase in total cell number but does not change cell density. Although an effect on cell size would appear likely given the function of Pten, and indeed, should be examined in future experiments, these observations indicate that hyperpla- 
sia is the primary driver of increased cortical mass caused by Pten haploinsufficiency. We find this result rather surprising given that increased neuronal soma size (hypertrophy) is well linked with brain overgrowth caused by homozygous mutations in Pten (Goberdhan et al., 1999; Backman et al., 2001; Groszer et al., 2001; Kwon et al., 2001; Fraser et al., 2004; Kazdoba et al., 2012). Consistent with these reports, we find a profound decrease in cellular density in the cerebral cortex of mice with conditional homozygous Pten mutation, indicating hypertrophy. Strikingly, there is no significant difference in total cortical cell number between conditional heterozygous and homozygous Pten mutations, despite the large increase in cortical mass between these two genotypes. We interpret this as follows: mutations that result in Pten levels or function $\geq 50 \%$ of WT (e.g., heterozygous lossof-function alleles) drive changes in overall brain size primarily via hyperplasia, whereas mutations that result in Pten levels or function $<50 \%$ of WT (e.g., homozygous loss-of-function alleles) drive changes in overall brain size via combined hyperplasia and hypertrophy. In agreement with this possibility, haploinsufficiency for Ctnnb1, but not Mtor or Rptor, is capable of suppressing cortical overgrowth in a Pten $^{+/-}$background. Furthermore, mTORC1 activity, as indicated by p-S6 levels, is strongly potentiated in the newborn cerebral cortex of mice with conditional homozygous, but not heterozygous, Pten mutations. Our findings indicate that homozygous and heterozygous Pten mutations result in categorically different effects as regards cell density and mTOR-p-S6 signaling in the developing brain.

\section{References}

Aberle H, Bauer A, Stappert J, Kispert A, Kemler R (1997) $\beta$-Catenin is a target for the ubiquitin-proteasome pathway. EMBO J 16:3797-3804. CrossRef Medline

Arnett HA, Fancy SP, Alberta JA, Zhao C, Plant SR, Kaing S, Raine CS, Rowitch DH, Franklin RJ, Stiles CD (2004) bHLH transcription factor Olig1 is required to repair demyelinated lesions in the CNS. Science 306: 2111-2115. CrossRef Medline

Backman SA, Stambolic V, Suzuki A, Haight J, Elia A, Pretorius J, Tsao MS, Shannon P, Bolon B, Ivy GO, Mak TW (2001) Deletion of Pten in mouse brain causes seizures, ataxia and defects in soma size resembling Lhermitte-Duclos disease. Nat Genet 29:396-403. CrossRef Medline

Bonaguidi MA, Wheeler MA, Shapiro JS, Stadel RP, Sun GJ, Ming GL, Song H (2011) In vivo clonal analysis reveals self-renewing and multipotent adult neural stem cell characteristics. Cell 145:1142-1155. CrossRef Medline

Boylan CB, Blue ME, Hohmann CF (2007) Modeling early cortical serotonergic deficits in autism. Behav Brain Res 176:94-108. CrossRef Medline

Brault V, Moore R, Kutsch S, Ishibashi M, Rowitch DH, McMahon AP, Sommer L, Boussadia O, Kemler R (2001) Inactivation of the betacatenin gene by Wnt1-Cre-mediated deletion results in dramatic brain malformation and failure of craniofacial development. Development 128: 1253-1264. Medline

Butler MG, Dasouki MJ, Zhou XP, Talebizadeh Z, Brown M, Takahashi TN, Miles JH, Wang CH, Stratton R, Pilarski R, Eng C (2005) Subset of individuals with autism spectrum disorders and extreme macrocephaly associated with germline PTEN tumour suppressor gene mutations. J Med Genet 42:318-321. CrossRef Medline

Buxbaum JD, Cai G, Chaste P, Nygren G, Goldsmith J, Reichert J, Anckarsater H, Rastam M, Smith CJ, Silverman JM, Anckarsäter H, Rastam M, Smith CJ, Silverman JM, Hollander E, Leboyer M, Gillberg C, Verloes A, Betancur C (2007) Mutation screening of the PTEN gene in patients with autism spectrum disorders and macrocephaly. Am J Med Genet B Neuropsychiatr Genet 144B:484-491. CrossRef Medline

Carper RA, Courchesne E (2005) Localized enlargement of the frontal cortex in early autism. Biol Psychiatry 57:126-133. CrossRef Medline

Carper RA, Moses P, Tigue ZD, Courchesne E (2002) Cerebral lobes in autism: early hyperplasia and abnormal age effects. Neuroimage 16:10381051. CrossRef Medline

Chenn A, Walsh CA (2002) Regulation of cerebral cortical size by control of cell cycle exit in neural precursors. Science 297:365-369. CrossRef Medline
Chow ML, Pramparo T, Winn ME, Barnes CC, Li HR, Weiss L, Fan JB, Murray S, April C, Belinson H, Fu XD, Wynshaw-Boris A, Schork NJ, Courchesne E (2012) Age-dependent brain gene expression and copy number anomalies in autism suggest distinct pathological processes at young versus mature ages. PLoS Genet 8:e1002592. CrossRef Medline

Chung JH, Eng C (2005) Nuclear-cytoplasmic partitioning of phosphatase and tensin homologue deleted on chromosome 10 (PTEN) differentially regulates the cell cycle and apoptosis. Cancer Res 65:8096-8100. CrossRef Medline

Clevers H, Nusse R (2012) Wnt/beta-catenin signaling and disease. Cell 149: 1192-1205. CrossRef Medline

Clipperton-Allen AE, Page DT (2014) Pten haploinsufficient mice show broad brain overgrowth but selective impairments in autism-relevant behavioral tests. Hum Mol Genet 23:3490-3505. CrossRef Medline

Courchesne E (2002) Abnormal early brain development in autism. Mol Psychiatry 7[Suppl 2]:S21-S23.

Courchesne E, Pierce K, Schumann CM, Redcay E, Buckwalter JA, Kennedy DP, Morgan J (2007) Mapping early brain development in autism. Neuron 56:399-413. CrossRef Medline

Courchesne E, Mouton PR, Calhoun ME, Semendeferi K, Ahrens-Barbeau C, Hallet MJ, Barnes CC, Pierce K (2011) Neuron number and size in prefrontal cortex of children with autism. JAMA 306:2001-2010. CrossRef Medline

Cross DA, Alessi DR, Cohen P, Andjelkovich M, Hemmings BA (1995) Inhibition of glycogen synthase kinase-3 by insulin mediated by protein kinase B. Nature 378:785-789. CrossRef Medline

de Ligt J, Willemsen MH, van Bon BW, Kleefstra T, Yntema HG, Kroes T, Vulto-van Silfhout AT, Koolen DA, de Vries P, Gilissen C, del Rosario M, Hoischen A, Scheffer H, de Vries BB, Brunner HG, Veltman JA, Vissers LE (2012) Diagnostic exome sequencing in persons with severe intellectual disability. N Engl J Med 367:1921-1929. CrossRef Medline

Diao L, Chen YG (2007) PTEN, a general negative regulator of cyclin D expression. Cell Res 17:291-292. CrossRef Medline

Dubruc E, Putoux A, Labalme A, Rougeot C, Sanlaville D, Edery P (2014) A new intellectual disability syndrome caused by CTNNB1 haploinsufficiency. Am J Med Genet A 164A:1571-1575. CrossRef Medline

Duerr EM, Rollbrocker B, Hayashi Y, Peters N, Meyer-Puttlitz B, Louis DN, Schramm J, Wiestler OD, Parsons R, Eng C, von Deimling A (1998) PTEN mutations in gliomas and glioneuronal tumors. Oncogene 16 : 2259-2264. CrossRef Medline

Edmonson C, Ziats MN, Rennert OM (2014) Altered glial marker expression in autistic post-mortem prefrontal cortex and cerebellum. Mol Autism 5:3. CrossRef Medline

Fang WQ, Chen WW, Jiang L, Liu K, Yung WH, Fu AK, Ip NY (2014) Overproduction of upper-layer neurons in the neocortex leads to autismlike features in mice. Cell Rep 9:1635-1643. CrossRef Medline

Ferrer-Vaquer A, Piliszek A, Tian G, Aho RJ, Dufort D, Hadjantonakis AK (2010) A sensitive and bright single-cell resolution live imaging reporter of Wnt $/ \beta$-catenin signaling in the mouse. BMC Dev Biol 10:121. CrossRef Medline

Fraser MM, Zhu X, Kwon CH, Uhlmann EJ, Gutmann DH, Baker SJ (2004) Pten loss causes hypertrophy and increased proliferation of astrocytes in vivo. Cancer Res 64:7773-7779. CrossRef Medline

Frazier TW, Embacher R, Tilot AK, Koenig K, Mester J, Eng C (2014) Molecular and phenotypic abnormalities in individuals with germline heterozygous PTEN mutations and autism. Mol Psychiatry. Advance online publication. Accessed Oct. 7, 2014. doi: 10.1038/mp.2014.125. CrossRef Medline

Goberdhan DC, Paricio N, Goodman EC, Mlodzik M, Wilson C (1999) Drosophila tumor suppressor PTEN controls cell size and number by antagonizing the Chico/PI3-kinase signaling pathway. Genes Dev 13: 3244-3258. CrossRef Medline

Gorski JA, Talley T, Qiu M, Puelles L, Rubenstein JL, Jones KR (2002) Cortical excitatory neurons and glia, but not GABAergic neurons, are produced in the Emx1-expressing lineage. J Neurosci 22:6309-6314. Medline

Groszer M, Erickson R, Scripture-Adams DD, Lesche R, Trumpp A, Zack JA, Kornblum HI, Liu X, Wu H (2001) Negative regulation of neural stem/ progenitor cell proliferation by the Pten tumor suppressor gene in vivo. Science 294:2186-2189. CrossRef Medline

Guertin DA, Stevens DM, Thoreen CC, Burds AA, Kalaany NY, Moffat J, Brown M, Fitzgerald KJ, Sabatini DM (2006) Ablation in mice of the mTORC components raptor, rictor, or mLST8 reveals that mTORC2 is 
required for signaling to Akt-FOXO and PKCalpha, but not S6K1. Dev Cell 11:859-871. CrossRef Medline

Hazlett HC, Poe M, Gerig G, Smith RG, Provenzale J, Ross A, Gilmore J, Piven J (2005) Magnetic resonance imaging and head circumference study of brain size in autism: birth through age 2 years. Arch Gen Psychiatry 62: 1366-1376. CrossRef Medline

Herculano-Houzel S, Lent R (2005) Isotropic fractionator: a simple, rapid method for the quantification of total cell and neuron numbers in the brain. J Neurosci 25:2518-2521. CrossRef Medline

Huang W, Chang HY, Fei T, Wu H, Chen YG (2007) GSK3 beta mediates suppression of cyclin D2 expression by tumor suppressor PTEN. Oncogene 26:2471-2482. CrossRef Medline

Imai Y, Ibata I, Ito D, Ohsawa K, Kohsaka S (1996) A novel gene ibal in the major histocompatibility complex class III region encoding an EF hand protein expressed in a monocytic lineage. Biochem Biophys Res Commun 224:855-862. CrossRef Medline

Kanner L (1943) Autistic disturbances of affective contact. Nervous Child 2:217-250.

Kazdoba TM, Sunnen CN, Crowell B, Lee GH, Anderson AE, D’Arcangelo G (2012) Development and characterization of NEX- Pten, a novel forebrain excitatory neuron-specific knockout mouse. Dev Neurosci 34:198209. CrossRef Medline

Klein S, Sharifi-Hannauer P, Martinez-Agosto JA (2013) Macrocephaly as a clinical indicator of genetic subtypes in autism. Autism Res 6:51-56. CrossRef Medline

Kriegstein A, Alvarez-Buylla A (2009) The glial nature of embryonic and adult neural stem cells. Annu Rev Neurosci 32:149-184. CrossRef Medline

Kwon CH, Zhu X, Zhang J, Knoop LL, Tharp R, Smeyne RJ, Eberhart CG, Burger PC, Baker SJ (2001) Pten regulates neuronal soma size: a mouse model of Lhermitte-Duclos disease. Nat Genet 29:404-411. CrossRef Medline

Lesche R, Groszer M, Gao J, Wang Y, Messing A, Sun H, Liu X, Wu H (2002) Cre/loxP-mediated inactivation of the murine Pten tumor suppressor gene. Genesis 32:148-149. CrossRef Medline

Li J, Yen C, Liaw D, Podsypanina K, Bose S, Wang SI, Puc J, Miliaresis C, Rodgers L, McCombie R, Bigner SH, Giovanella BC, Ittmann M, Tycko B, Hibshoosh H, Wigler MH, Parsons R (1997) PTEN, a putative protein tyrosine phosphatase gene mutated in human brain, breast, and prostate cancer. Science 275:1943-1947. CrossRef Medline

Li L, Liu F, Salmonsen RA, Turner TK, Litofsky NS, Di Cristofano A, Pandolfi PP, Jones SN, Recht LD, Ross AH (2002) PTEN in neural precursor cells: regulation of migration, apoptosis, and proliferation. Mol Cell Neurosci 20:21-29. CrossRef Medline

McBride KL, Varga EA, Pastore MT, Prior TW, Manickam K, Atkin JF, Herman GE (2010) Confirmation study of PTEN mutations among individuals with autism or developmental delays/mental retardation and macrocephaly. Autism Res 3:137-141. CrossRef Medline

Migheli A, Cordera S, Bendotti C, Atzori C, Piva R, Schiffer D (1999) S-100beta protein is upregulated in astrocytes and motor neurons in the spinal cord of patients with amyotrophic lateral sclerosis. Neurosci Lett 261:25-28. CrossRef Medline

Morgan JT, Chana G, Pardo CA, Achim C, Semendeferi K, Buckwalter J, Courchesne E, Everall IP (2010) Microglial activation and increased microglial density observed in the dorsolateral prefrontal cortex in autism. Biol Psychiatry 68:368-376. CrossRef Medline

Naruse I, Keino H (1995) Apoptosis in the developing CNS. Prog Neurobiol 47:135-155. CrossRef Medline

Ohsawa K, Imai Y, Kanazawa H, Sasaki Y, Kohsaka S (2000) Involvement of Ibal in membrane ruffling and phagocytosis of macrophages/microglia. J Cell Sci 113:3073-3084. Medline

O'Roak BJ, Vives L, Fu W, Egertson JD, Stanaway IB, Phelps IG, Carvill G, Kumar A, Lee C, Ankenman K, Munson J, Hiatt JB, Turner EH, Levy R, O’Day DR, Krumm N, Coe BP, Martin BK, Borenstein E, Nickerson DA, et al. (2012) Multiplex targeted sequencing identifies recurrently mutated genes in autism spectrum disorders. Science 338:1619-1622. CrossRef Medline

Page DT, Kuti OJ, Prestia C, Sur M (2009) Haploinsufficiency for Pten and serotonin transporter cooperatively influences brain size and social behavior. Proc Natl Acad Sci U S A 106:1989-1994. CrossRef Medline

Piven J, Arndt S, Bailey J, Andreasen N (1996) Regional brain enlargement in autism: a magnetic resonance imaging study. J Am Acad Child Adolesc Psychiatry 35:530-536. CrossRef Medline

Podsypanina K, Ellenson LH, Nemes A, Gu J, Tamura M, Yamada KM,
Cordon-Cardo C, Catoretti G, Fisher PE, Parsons R (1999) Mutation of Pten/Mmac1 in mice causes neoplasia in multiple organ systems. Proc Natl Acad Sci U S A 96:1563-1568. CrossRef Medline

Radu A, Neubauer V, Akagi T, Hanafusa H, Georgescu MM (2003) PTEN induces cell cycle arrest by decreasing the level and nuclear localization of cyclin D1. Mol Cell Biol 23:6139-6149. CrossRef Medline

Raznahan A, Wallace GL, Antezana L, Greenstein D, Lenroot R, Thurm A, Gozzi M, Spence S, Martin A, Swedo SE, Giedd JN (2013) Compared to what? Early brain overgrowth in autism and the perils of population norms. Biol Psychiatry 74:563-575. CrossRef Medline

Risson V, Mazelin L, Roceri M, Sanchez H, Moncollin V, Corneloup C, Richard-Bulteau H, Vignaud A, Baas D, Defour A, Freyssenet D, Tanti JF, Le-Marchand-Brustel Y, Ferrier B, Conjard-Duplany A, Romanino K, Bauché S, Hantaï D, Mueller M, Kozma SC, et al. (2009) Muscle inactivation of mTOR causes metabolic and dystrophin defects leading to severe myopathy. J Cell Biol 187:859-874. CrossRef Medline

Schumann CM, Bloss CS, Barnes CC, Wideman GM, Carper RA, Akshoomoff N, Pierce K, Hagler D, Schork N, Lord C, Courchesne E (2010) Longitudinal magnetic resonance imaging study of cortical development through early childhood in autism. J Neurosci 30:4419-4427. CrossRef Medline

Stambolic V (2002) PTEN: a new twist on beta-catenin? Trends Pharmacol Sci 23:104-106. CrossRef Medline

Stessman HA, Bernier R, Eichler EE (2014) A genotype-first approach to defining the subtypes of a complex disease. Cell 156:872-877. CrossRef Medline

Stiles B, Groszer M, Wang S, Jiao J, Wu H (2004) PTENless means more. Dev Biol 273:175-184. CrossRef Medline

Sun H, Lesche R, Li DM, Liliental J, Zhang H, Gao J, Gavrilova N, Mueller B, Liu X, Wu H (1999) PTEN modulates cell cycle progression and cell survival by regulating phosphatidylinositol 3,4,5,-trisphosphate and Akt/ protein kinase B signaling pathway. Proc Natl Acad Sci U S A 96:61996204. CrossRef Medline

Suzuki K, Sugihara G, Ouchi Y, Nakamura K, Futatsubashi M, Takebayashi K, Yoshihara Y, Omata K, Matsumoto K, Tsuchiya KJ, Iwata Y, Tsujii M, Sugiyama T, Mori N (2013) Microglial activation in young adults with autism spectrum disorder. JAMA Psychiatry 70:49-58. CrossRef Medline

Teng DH, Hu R, Lin H, Davis T, Iliev D, Frye C, Swedlund B, Hansen KL, Vinson VL, Gumpper KL, Ellis L, El-Naggar A, Frazier M, Jasser S, Langford LA, Lee J, Mills GB, Pershouse MA, Pollack RE, Tornos C, et al. (1997) MMAC1/PTEN mutations in primary tumor specimens and tumor cell lines. Cancer Res 57:5221-5225. Medline

Thompson BA, Tremblay V, Lin G, Bochar DA (2008) CHD8 is an ATPdependent chromatin remodeling factor that regulates beta-catenin target genes. Mol Cell Biol 28:3894-3904. CrossRef Medline

Varga EA, Pastore M, Prior T, Herman GE, McBride KL (2009) The prevalence of PTEN mutations in a clinical pediatric cohort with autism spectrum disorders, developmental delay, and macrocephaly. Genet Med 11: 111-117. CrossRef Medline

Vargas DL, Nascimbene C, Krishnan C, Zimmerman AW, Pardo CA (2005) Neuroglial activation and neuroinflammation in the brain of patients with autism. Ann Neurol 57:67-81. CrossRef Medline

Voineagu I, Wang X, Johnston P, Lowe JK, Tian Y, Horvath S, Mill J, Cantor RM, Blencowe BJ, Geschwind DH (2011) Transcriptomic analysis of autistic brain reveals convergent molecular pathology. Nature 474:380384. CrossRef Medline

Wassink TH, Hazlett HC, Epping EA, Arndt S, Dager SR, Schellenberg GD, Dawson G, Piven J (2007) Cerebral cortical gray matter overgrowth and functional variation of the serotonin transporter gene in autism. Arch Gen Psychiatry 64:709-717. CrossRef Medline

Yokoo H, Nobusawa S, Takebayashi H, Ikenaka K, Isoda K, Kamiya M, Sasaki A, Hirato J, Nakazato Y (2004) Anti-human Olig2 antibody as a useful immunohistochemical marker of normal oligodendrocytes and gliomas. Am J Pathol 164:1717-1725. CrossRef Medline

Zeidán-Chuliá F, Salmina AB, Malinovskaya NA, Noda M, Verkhratsky A, Moreira JC (2014) The glial perspective of autism spectrum disorders. Neurosci Biobehav Rev 38:160-172. CrossRef Medline

Zhou J, Parada LF (2012) PTEN signaling in autism spectrum disorders. Curr Opin Neurobiol 22:873-879. CrossRef Medline

Zilbovicius M, Garreau B, Samson Y, Remy P, Barthélémy C, Syrota A, Lelord G (1995) Delayed maturation of the frontal cortex in childhood autism. Am J Psychiatry 152:248-252. CrossRef Medline 